\title{
Controls of climate, topography, vegetation, and lithology on drainage density extracted from high resolution topography data
}

\author{
Harish Sangireddy ${ }^{\mathrm{a}}$, Richard A. Carothers ${ }^{\mathrm{a}}$, Colin P. Stark ${ }^{\mathrm{b}}$, Paola \\ Passalacqua ${ }^{\mathrm{a}, 1}$ \\ ${ }^{a}$ Department of Civil, Architectural and Environmental Engineering, and Center for \\ Research in Water Resources, The University of Texas at Austin, Austin, TX \\ ${ }^{b}$ Lamont-Doherty Earth Observatory, Columbia University, USA.
}

\begin{abstract}
Mark Melton in 1957 found that climate, basin morphometry, and surficial variables control drainage density $\left(D_{d}\right)$, but differences observed between field surveyed channels and those mapped on topographic contours or blue lines left doubts on these results. Later, several landscape evolution modeling and observational studies have analyzed the behavior of $D_{d}$. However, only a few studies have been performed over a large number of landscapes of different characteristics and have relied on high resolution topography data.

We revisit Melton's hypothesis by using meter resolution digital terrain models (DTMs) in 101 subbasins in the USA. We first propose a dimensionless drainage density $\left(D_{d d}\right)$ metric based on the ratio of likely channelized pixels to total number of basin pixels which has the advantage of eliminating the computation of the channel network. Our analysis shows that $D_{d d}$ is a weak scaling function of the input DTM resolution compared to the classic dimensional $D_{d}$ metric (ratio of total channel length to total basin area). We analyze the correlation of $D_{d d}$ and mean annual precipitation $(M A P)$ with a Gaussian mixture model which identifies two sub-groups displaying different correlation; negative in arid and semi-arid environments, and positive in humid environments. The transition in correlation is around $1100 \pm 100 \mathrm{~mm} / \mathrm{yr}$
\end{abstract}

\footnotetext{
${ }^{1}$ Corresponding author: P. Passalacqua, Department of Civil, Architectural and Environmental Engineering and Center for Research in Water Resources, The University of Texas at Austin, 301 E. Dean Keeton St. STOP C1700, Austin, TX 78712-2100, USA.(paola@austin.utexas.edu)
}

Preprint submitted to Journal of Hydrology

February 15, 2016

(C) 2016. This manuscript version is made available under the Elsevier user license http://www.elsevier.com/open-access/userlicense/1.0/ 
of $M A P$ and is accompanied by the occurrence of thick soil layers and high available water capacity that promote dense vegetation cover $\left(V_{c o v}\right)$ and low $D_{d d}$. While small variation in $D_{d d}$ is observed across vegetation types, increasing $V_{\text {cov }}$ corresponds to decreasing $D_{d d}$. We also further explore the relationship between $D_{d d}$ and relief $R$, and $D_{d d}$ and lithology. $D_{d d}$ and $R$ are weakly correlated in arid and semi-arid environments, while they have strong positive correlation in humid environments. No significant correlation is found between $D_{d d}$ and lithology although the results are likely affected by our sample choice.

Keywords: drainage density, climate, topography, lidar

\section{Introduction}

As a unique property of the landscape, drainage density $\left(D_{d}\right)$ relates the underlying geomorphic processes acting in a catchment to its topography (Moglen et al., 1998). Usually expressed as the ratio of total channel length to total catchment area (Horton, 1932), $D_{d}$ is controlled by local lithology (Carlston, 1963; Kelson \& Wells, 1989; Melton, 1957; Talling \& Sowter, 1999), topography (Tucker \& Bras, 1998; Oguchi, 1997a), vegetation (Luoto, 2007; Chorley, 1957; Moglen et al., 1998; Melton, 1957; Collins \& Bras, 2010; Istanbulluoglu \& Bras, 2005) and regional climatic patterns (Melton, 1957; Abrahams, 1984, 1972b; Daniel, 1981; Gregory \& Walling, 1968; Madduma Bandara, 1974; Chorley, 1957; Moglen et al., 1998; Smith et al., 2013; Chadwick et al., 2013).

Field studies and modeling efforts have been used to isolate and understand the controls of climate, topography, vegetation, and lithology on $D_{d}$. One such extensive field study was conducted by Melton (1957) over 90 basins in Arizona, Colorado, New Mexico and Utah. Topographic contour maps $[1: 24,000]$ were used to measure catchment slope, relief $(R)$, and $D_{d}$. The Thornthwaite precipitation-evaporation (P-E) index (Thornthwaite, 1931) was used to represent regional climatic patterns, while relative infiltration capacity, soil strength, and percent bare were used to represent soil and vegetation characteristics. Through multivariate regression and correlation analysis, Melton (1957) observed that $D_{d}$ increased with increasing percent bare and runoff $(I)$ but decreased with increasing P-E index and infiltration capacity. Some variation in $D_{d}$ by lithology type was also observed; average $D_{d}$ for shale and schist was well above the observed mean $D_{d}$, whereas the 
values for limestone and acidic volcanic rocks were well below mean $D_{d}$.

Abrahams (1984) extended this analysis over a wider range of P-E index and observed that $D_{d}$ varied inversely with $\mathrm{P}-\mathrm{E}$ index in semi-arid regions while increased with increasing P-E index in humid environments. This reversal in trend was attributed to the local vegetation cover $\left(V_{c o v}\right)$. The dueling control of vegetation and runoff over $D_{d}$ with increasing mean annual precipitation $(M A P)$ was also studied by Istanbulluoglu \& Bras (2005) who showed with numerical experiments that contrasting differences between drainage networks in landscapes with and without vegetation cover existed. For no $V_{c o v}$ their simulations generated low relief highly dissected landscapes, while a static $V_{\text {cov }}$ produced a less dissected landscape. Collins \& Bras (2010) later summarized the feedback of vegetation and runoff under varying $M A P$ in a schematic representation showing an initial increase in drainage density in arid areas, followed by a decrease in semi-arid regions, and an increase in humid environments.

Drainage density $\left(D_{d}\right)$ is defined as the ratio of total channel length in a catchment to total catchment area (Horton, 1932). Computation of $D_{d}$ needs prior knowledge of channel head locations followed by a robust method for channel centerline extraction. Coarse resolution digital elevation models (DEMs) fail to capture first order channels which are essential for the transport of runoff and sediment from hillslopes to valleys. The inability to accurately detect channel networks in coarse resolution DEMs affects the computation of $D_{d}$ causing strong discrepancy with field mapped results (Morisawa, 1957, 1961; Schneider, 1961; Li \& Wong, 2010; Goulden et al., 2014). With the recent availability of high resolution topography (HRT) data, we have the opportunity to analyze drainage density at spatial resolutions commensurate with the underlying process regimes. HRT data have changed the way landscapes are analyzed and have increased our ability to infer processes from landscapes and extract landscape features at scales comparable to the underlying catchment processes (Lin \& Oguchi, 2004, Roering et al., 2013; Glennie et al., 2013; Passalacqua et al., 2014; Tarolli, 2014; Harpold et al., 2015, Passalacqua et al., 2015).

Channel networks and channel heads can be automatically and objectively extracted from HRT data (Lashermes et al., 2007; Tarolli \& Dalla Fontana, 2009; Passalacqua et al., 2010b a; Pelletier, 2013; Sangireddy et al., 2016) opening up the possibility of measuring $D_{d}$ objectively and revisiting the Melton (1957) hypothesis. Similarly, processes such as tree throws and root decay, which control sediment generation in a basin and indirectly influence 
the extent of landscape dissection, can be inferred successfully from HRT data (Gabet et al., 2003; Roering et al., 2004; Gabet \& Mudd, 2010). Vegetation properties such as mean tree height, canopy density, above ground biomass (AGB) can also be computed from these datasets (Nilsson, 1996; Clark et al., 2011; Pelletier et al., 2011; Hurst et al., 2013).

Basin lithology affects the extent of landscape dissection. MAP and available water capacity $(A W C)$ are important factors influencing rock weathering and soil thickness $(T H I C K)$. By analyzing the behavior of soil parameters, relief $(R)$, and vegetation cover $\left(V_{\text {cov }}\right)$ with increasing $M A P$ we can capture how climate controls these variables and how these variables affect the correlation of $D_{d}$ and $M A P$. Also, soil physical properties such as porosity, thickness, and pore size are controlled indirectly by climate (Chadwick et al., 2013) and determine water supply that strongly influences plant growth. Similarly, the correlation between topographic relief and $D_{d}$ is of particular interest as it helps understand the relationship between erosion rates and patterns of channelization critical for testing eco-geomorphic landscape evolution models (Oguchi, 1997a; Howard, 1998; Tucker \& Bras, 1998).

Melton's hypothesis has been cited numerous times in the literature. However, to our knowledge, this hypothesis has not been investigated using high-resolution lidar data and new technologies for data processing and methods for channel identification. This paper presents a new non-dimensional metric of drainage density, illustrates its robustness with respect to data resolution, and uses it for analyzing the relationship between drainage density and its controlling factors. In particular, the goals of this study are to: (i) propose a dimensionless measure of drainage density $D_{d d}$ based on the number of likely channelized basin pixels, eliminating the need for computation of the channel network and reducing the resolution dependence of drainage density, and (ii) by using a large high resolution data set across the USA, revisit Melton's hypothesis and examine the controls of climate, topography, vegetation, and lithology on drainage density. The underlying hypothesis of our study is that drainage density carries strong, codependent signatures of $M A P, R, V_{c o v}$, vegetation type, lithology, and rock strength. Such signatures can be objectively determined by analyzing HRT data.

We test this hypothesis by mapping drainage density over meter resolution datasets with the GeoNet method (https://sites.google.com/site/ geonethome, Passalacqua et al. (2010b); Sangireddy et al. (2016)) in 101 subbasins across 13 states in the USA in combination with best available spatial resolution maps of precipitation, soil, geology, and land cover. The choice of 
the subbasins was constrained by the availability of HRT data and the need to cover a wide range of climatic regimes. The availability of spatial maps of precipitation, soil, geology, and land cover was also considered. In addition, we focused our analysis on basins that are not severely urbanized, enforcing this criterion through visual inspection of aerial imagery.

The paper is organized as follows. After introducing the datasets used in this work (Section 2), we propose a dimensionless drainage density metric and analyze its behavior through scales, followed by an explanation of the method used to estimate canopy cover (Section 3). We analyze the correlation between drainage density and several climatic, topographic, vegetational, and geologic parameters (Section 4), followed by a discussion of the results (Section 5). Finally, we state the conclusions of this work (Section 6).

\section{Study areas and data description}

We analyze a total of 101 subbasins located across 13 states (Figure11). HRT data were obtained from OpenTopography (http://www.opentopography. org/) at $1 \mathrm{~m}$ resolution (airborne lidar), except for four basins in Arizona and four basins in Utah, for which HRT data were obtained from the National Elevation Dataset (NED) at $3 \mathrm{~m}$ resolution and re-sampled to $1 \mathrm{~m}$ resolution by using the nearest neighbor method. The eight basins from NED were included in our analysis as these regions were analyzed by Melton (1957). Lidar point density varied considerably over the basins depending on the date of the lidar survey as well as the local ground cover. Rasters were generated from the lidar point clouds by creating a TIN (Triangulated Irregular Network) with an interpolation algorithm called TIN streaming (http://www.cs.unc.edu/ isenburg/tin2dem/).

As explained in Section 3.3, the estimation of vegetation density relies on lidar data classified into ground returns (bare earth DTMs) and non-ground returns (Digital Surface Models DSMs). The ground and non-ground returns are only available for the datasets obtained from OpenTopography.

The subbasins analyzed are all of size $0.12 \mathrm{~km}^{2}$. A larger box of data of size $2 \mathrm{~km}^{2}$ was cut around each subbasin to perform operations such as filtering and computation of topographic attributes without creation of edge effects at the subbasin boundary. Information on the lithology, vegetation type, and climate for each of the sub basins included in our analysis is available in the Supplementary Information. 


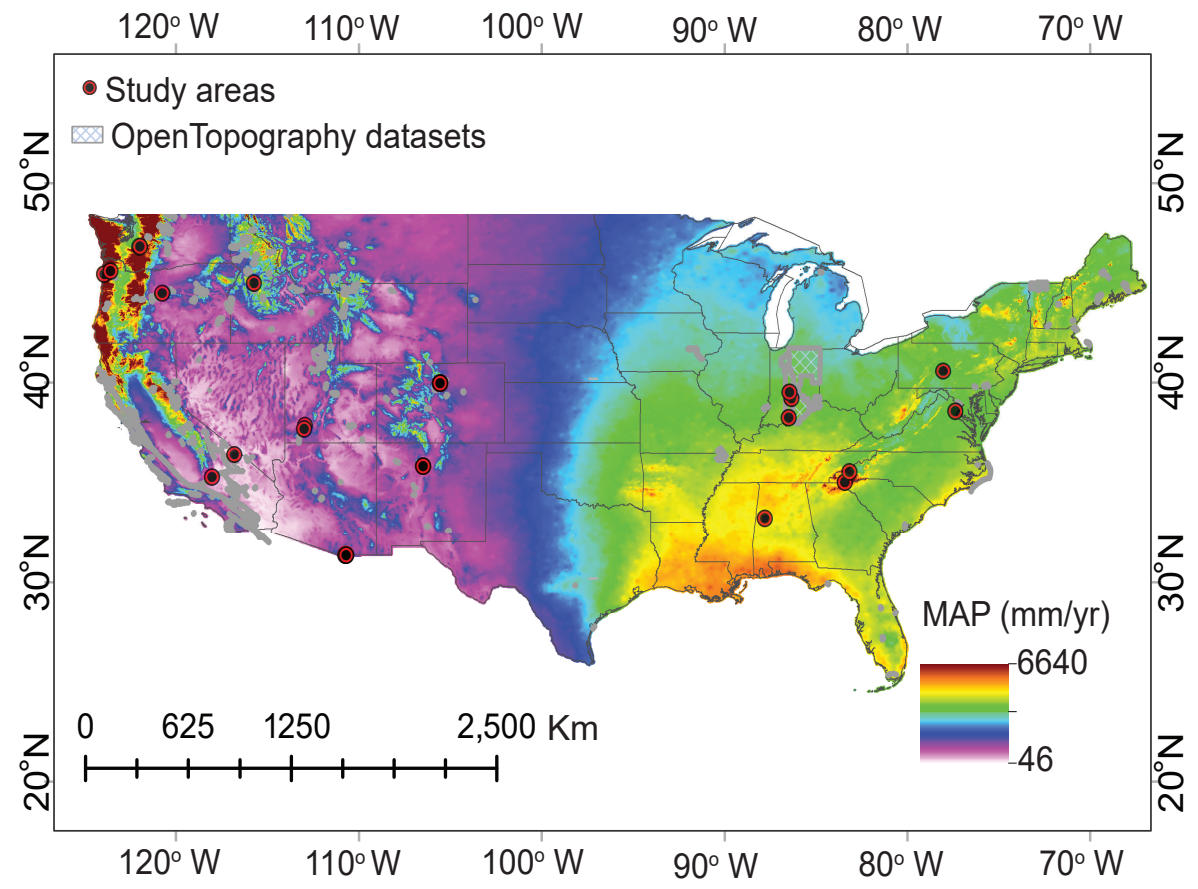

Figure 1: Location of study areas (red circles) with outline of available lidar datasets on OpenTopography (grey polygons). The $M A P(\mathrm{~mm} / \mathrm{yr})$ in the United States is also shown in the background.

Mean annual precipitation $(M A P)$ was downloaded from the gridded PRISM climate dataset (http://prism.oregonstate.edu) available at 800 m resolution for the period $1981-2010$. Runoff intensity $(I)$ was computed as $I=P-f+5$ (Melton, 1957), where $P$ are 5 year, 1 hour precipitation frequency depths (inches), $f$ is infiltration capacity (in/hr), and 5 is a constant added to keep the runoff intensity positive. The precipitation frequency depths $(P F D)$ available as gridded GIS datasets and prepared from partial duration series for $1 \mathrm{hr}$ duration storms with 5 year return period, were downloaded from the NOAA precipitation frequency data server (http://hdsc.nws.noaa.gov/hdsc/pfds/index.html). The basins from Washington, Oregon and Idaho were excluded from the correlation analysis between $D_{d}$ and $I$ as 5 year 1 hour duration PFDs were not available.

Rock strength and lithology were determined from state geological maps downloaded from the Mineral Resources On-Line Spatial Data hosted by 
the U.S. Geological Survey (USGS) at http://mrdata.usgs .gov/geology/ state. The dominant rock type and age of the rocks were obtained for each analyzed basin. The Uniaxial Compressive Strength (UCS) (MPa) reported by the International Society for Rock Mechanics (ISRM) was used as a measure of rock strength (Ulusay \& Hudson, 2007). The low, average, and high $U C S(\mathrm{MPa})$ values for each rock type were recorded and the average $U C S$ was used for arranging basins by rock strength.

Soil parameters such as available water capacity $(A W C)$ (amount of water that a soil can store, measured in inches/inch), soil permeability (PERM) (in/hr), and soil thickness (THICK) (in) were obtained from the USDA STATSGO soil database (SoilSurveyStaff, 2014). All soil and geological maps were accessed at the available scale of 1:250,000. The soil permeability (PERM) reported in inches/hr was converted to $\mathrm{mm} / \mathrm{hr}$ and used as infiltration capacity $(\mathrm{mm} / \mathrm{hr})(f)$ in the estimation of runoff $(I)$. The map of North American Land Cover (2010) at the available spatial resolution of $250 \mathrm{~m}$ was used to derive land cover information (http://www.cec.org/). The North American Land Cover Database has 19 level II land cover classes defined using the land cover classification system developed by the Food and Agriculture Organization of the United States. The data was prepared from monthly aggregates of the 2010 Moderate Resolution Imaging Spectroradiometer (MODIS) satellite imagery. We use the defined classes within this dataset to identify vegetation types in our subbasins.

\section{Methods}

\subsection{Dimensionless drainage density}

Drainage density is commonly defined as the ratio of total length of channels to total basin area (Horton, 1932). This drainage density metric is scaledependent; as the data become coarser, $D_{d}$ decreases since channels below the grid resolution cannot be detected. In addition, the extraction of the channel network is required to compute the total channel length. To address these issues, we propose a dimensionless drainage density metric based on a recently developed approach to detect likely channelized pixels from the deviation of the curvature $[C]$ distribution from normal behavior (quantilequantile plot) (Lashermes et al., 2007: Passalacqua et al., 2010b) (Figure 2a). The deviation in the statistical behavior of $C$ is interpreted as transition from hillslopes to valleys and used to compute a curvature threshold $C_{t h}$ : 


$$
C_{t h}=\mu_{c}+T_{q q} * \sigma_{c}
$$

where $\mu_{c}$ and $\sigma_{c}$ are the mean and standard deviation of the catchment curvature values and $T_{q q}$ is the value of the standard normal variate at the deviation point (red dot in Figure 2a). Based on $C_{t h}$, we can identify the skeleton $[S]$ of likely channelized pixels defined as:

$$
S= \begin{cases}1 & C \in C>C_{t h} \\ 0 & C \in C<C_{t h}\end{cases}
$$

The set of points with $S=1$ are the likely channelized pixels in the landscape (Figure 2b). $T_{q q}, C$, and $S$ are automatically computed within GeoNet. The skeleton captures the extent of channelization in the basin and appears disrupted in correspondence of road crossings and other similar features detected in the HRT data. The skeleton is used within GeoNet to identify channel initiation points (as the upstream end points of the skeleton) and trace channel centerlines as geodesics.

Based on the skeleton $S$, a dimensionless drainage density $\left[D_{d d}\right]$ metric can be defined as:

$$
D_{d d}=\frac{P_{c h}}{P_{b}}
$$

where $P_{c h}$ indicates the total number of channelized pixels within the basin and $P_{b}$ the total number of basin pixels. This definition allows the estimation of drainage density without extracting the actual channel network centerline (Figure 2b). 
(a)

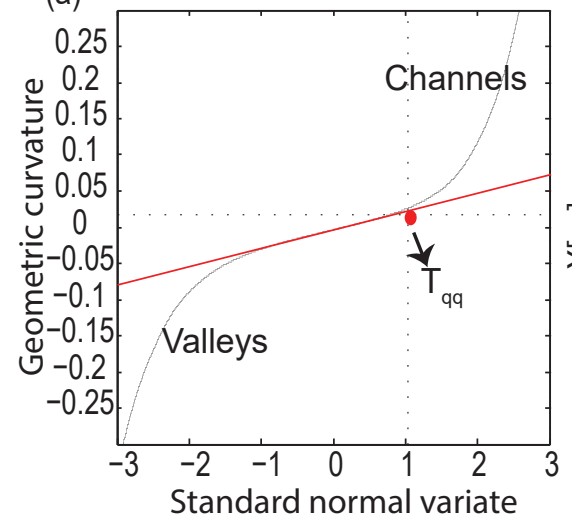

(b)

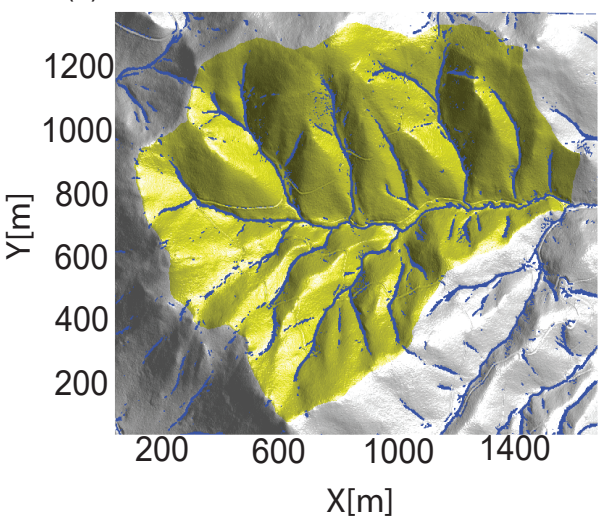

Figure 2: Identification of likely channelized pixels. (a) Comparison of curvature $(C)$ distribution to Normal distribution on a quantile-quantile plot for the Paso del Norte basin in New Mexico. The point at which the curvature distribution deviates from normal behavior is automatically identified within GeoNet $\left(T_{q q}\right.$, red dot) and used to compute a curvature threshold $C_{t h}$. All the basin pixels with $C \geq C_{t h}$ are identified as likely channelized pixels. (b) Hillshade of the Paso del Norte basin in New Mexico, skeleton of likely channelized pixels (blue), and basin area (yellow).

\subsection{Scaling analysis of drainage density}

We compare the behavior of $D_{d d}$ through scales to the classic drainage density metric:

$$
D_{g}=\frac{P_{c} * \delta}{P_{b} * \delta^{2}}
$$

where $\delta$ is the input digital terrain model (DTM) resolution, and $P_{c}$ is the total number of pixels along the channel centerline. Depending on the flow direction at any given pixel, $\delta$ is $\sqrt{2} \delta$ (when flow direction is along the diagonal of a grid cell) or just $\delta$ (when flow direction is along the horizontal or vertical faces of a grid cell).

The scaling analysis of $D_{d}$ is performed on 12 large watersheds. Lidar datasets of box size $\approx 5 \mathrm{~km}^{2}$ were downloaded and subbasins of size 0.9 $\mathrm{km}^{2}$ extracted from them. A larger area ensured the availability of enough pixels to extract $D_{d d}$ and $D_{g}$ at coarser resolutions. Each input lidar DTM was resampled to coarser resolutions $(2,3,4,5,6,8,10 \mathrm{~m})$ by using the nearest neighbor $(\mathrm{NN})$ method. Resolutions greater than $10 \mathrm{~m}$ were not considered as at coarse resolutions first and second order channels were not 
captured. Channel centerlines were extracted with the GeoNet method as curves of minimum cost (Passalacqua et al., 2010b) and $D_{g}\left(\mathrm{~m} / \mathrm{km}^{2}\right)$ was then calculated (equation 4).

The scaling analysis of $D_{g}$ and $D_{d d}$ shows that $D_{g}$ decreases with decreasing resolution (Figure 33 ) as channels smaller than the grid size cannot be detected. $D_{d d}$ instead shows a slight increase with data resolution (Figure $3 \mathrm{~b}$ ) which can be explained as follows. $P_{c h}$ (number of channelized pixels) and $P_{b}$ (number of basin pixels) decrease with decreasing resolution (Figure $3 \mathrm{c}, \mathrm{d})$. The analysis of the quantile-quantile plot of curvature across various input resolutions $(\delta)$ shows that as the input data are coarsened, the standard deviation of curvature $\left(\sigma_{c}\right)$ decays faster than the mean curvature $\left(\mu_{c}\right)$. Thus, the combined effect of $\sigma_{c}$ and $\mu_{c}$ forces the curvature threshold $\left(C_{t h}\right)$ to decrease with $\delta$ which causes more pixels to exceed $C_{t h}$ and be identified as possible channel pixels at coarser resolutions. Furthermore, the convergent topography of the datasets used in our analysis facilitates this behavior as the skeleton widens with decreasing resolution (coarser data). It should also be noted that filtering and the geodesic global minimization approach of GeoNet to centerline extraction prevent the artificial increase of channel centerline length usually observed when channels are extracted from HRT data with a steepest descent approach. In that case, the decreasing behavior of $D_{g}$ with data resolution would be more pronounced than what shown here.

We model the relationship between $D_{d}$ and $\delta$ with a model of the form (Rodríguez-Iturbe \& Rinaldo, 2001):

$$
D_{d}=a \delta^{\alpha}
$$

where $D_{d}$ is the drainage density measure $\left(D_{d d}\right.$ or $\left.D_{g}\right), \delta$ is the input DTM pixel resolution, and $\alpha$ is the slope of the model in $\log$ space $(\log (D)=$ $\log (a)+\alpha * \log (\delta))$. The regressed values for the $D_{d d}$ model are $a=0.072$ $\left[\mathrm{m}^{-\alpha}\right]$ and $\alpha=0.195$, while for the model $D_{g}$ are $a=1.882 e+04\left[\mathrm{~m}^{1-\alpha} / \mathrm{km}^{2}\right]$ and $\alpha=-0.435$. The values of $\alpha$ indicate that $D_{g}$ is approximately twice as strongly dependent on the input dataset resolution as $D_{d d}$. This analysis suggests that $D_{d d}$ is a better drainage density metric due to its dimensionless formulation, the ability to extract it objectively from lidar datasets without the need to extract channel centerlines, and a weaker scaling dependency on input data resolution $(\delta)$. 
(a)

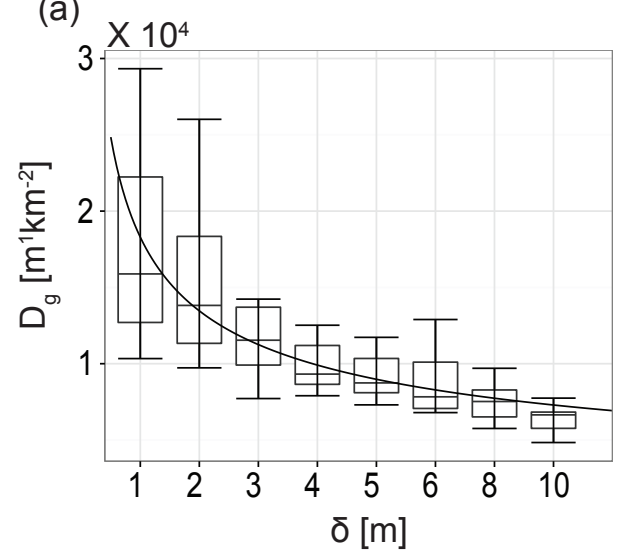

(c)

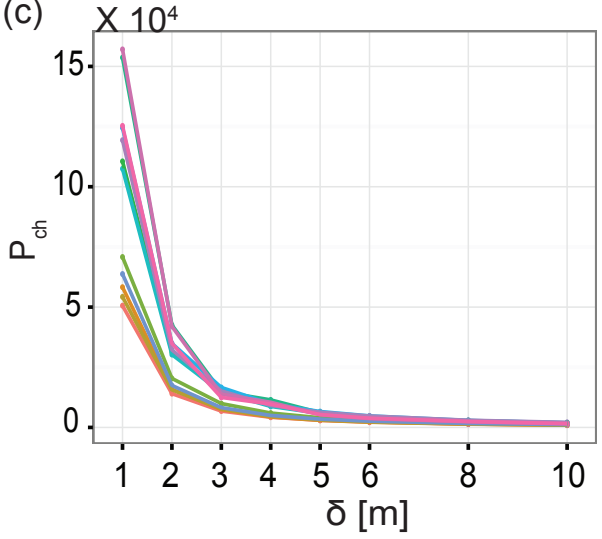

(b)

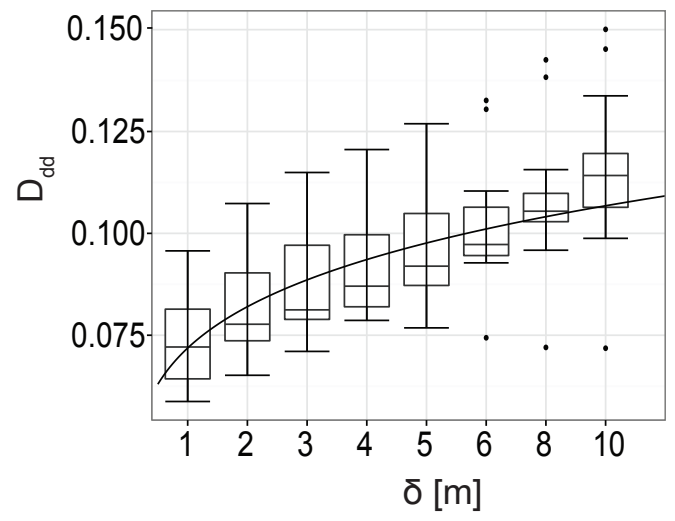

(d)

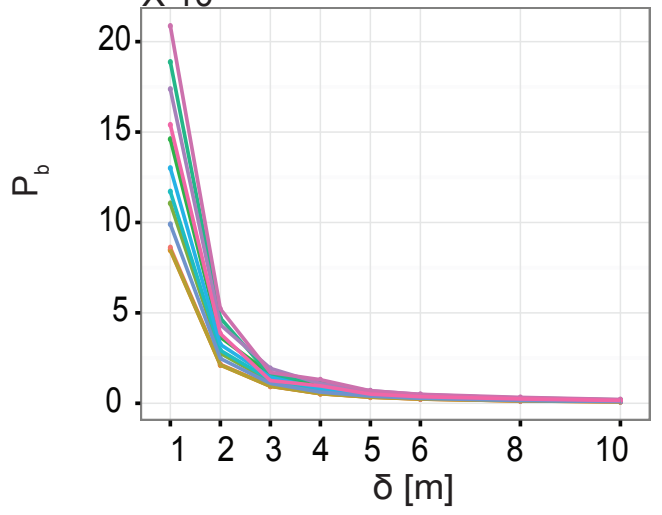

Figure 3: Scaling analysis of drainage density metrics. (a) Variation of $D_{g}\left(\mathrm{~m}^{1} \mathrm{~km}^{-2}\right)$ with input data resolution $(\delta)(\mathrm{m})$. For $D_{g}=a \delta^{\alpha}$ the regressed values are $a=1.882 e+$ $04\left[\mathrm{~m}^{1-\alpha} / \mathrm{km}^{2}\right]$ and $\alpha=-0.435$. (b) Variation in $D_{d d}$ with DTM resolution $(\delta)(\mathrm{m})$. For $D_{d d}=a \delta^{\alpha}$ the regressed values are $a=0.072\left[\mathrm{~m}^{-\alpha}\right]$ and $\alpha=0.195 . D_{d d}$ is less dependent on input DTM resolution compared to $D_{g}$. (c) Number of channelized pixels $\left(P_{c h}\right)$ identified for each landscape at each resolution $(\delta)(\mathrm{m})$. (d) Number of basin pixels $\left(P_{b}\right)$ identified for each landscape at each resolution $(\delta)(\mathrm{m})$.

\subsection{Estimation of vegetation density}

To estimate vegetation density, we use lidar data classified into ground returns (bare earth DTMs) and non-ground returns which we refer to here as Digital Surface Models (DSMs). Vegetation height at each pixel $\left(1 \mathrm{~m}^{2}\right)$ is computed as the difference between the DSM and DTM for each study re- 
gion. We express (DSM - DTM) as a percentage by comparing the number of pixels $\left(P_{\text {diff }}\right)$ with elevation greater than $3 \mathrm{~m}$ (only positive) to total number of basin pixels $\left(P_{b}\right)$ :

$$
V_{\text {cov }}=\frac{P_{\text {diff }}}{P_{b}} * 100
$$

A value of $V_{\text {cov }}=100 \%$ indicates that all the pixels in the DTM are above ground and the basin is completely covered with canopy (trees taller than 3 $\mathrm{m}$ ), while $V_{\text {cov }}=0 \%$ indicates no vegetation above $3 \mathrm{~m}$. The height difference of $3 \mathrm{~m}$ avoids the erroneous identification of vegetation due to errors in the DTM interpolation method in the case of low point density of the lidar survey. All the derived canopy density estimates compared visually well with satellite imagery. Since we restricted our analysis to non-urbanized landscapes, the simple difference of DSM - DTM can capture the extent of vegetation cover appropriately.

\section{Results}

\subsection{Correlation between $D_{d d}$, mean annual precipitation, and runoff inten-} sity

We analyze the correlation of $D_{d d}$ and $M A P$ with a Gaussian mixture model (McLachlan \& Peel, 2004). This model assigns a posterior probability to each point indicating the probability to belong to a cluster or sub population type. This approach is often preferred over the K-means clustering model as it is more general and also able to handle clusters of different size and that are correlated. In our analysis we used the gmdistribution class available in the MATLAB statistics toolbox.

The Gaussian mixture model of $D_{d d}$ and $M A P$ identifies two groups of subbasins with different trends. $D_{d d}$ initially decreases and then increases with increasing MAP (Figure 4a; the contour lines represent the posterior probability of a basin to belong to a cluster; the orientation of the contours indicates possible trends in each group but trends cannot be inferred solely based on the contours). The transition point between negative and positive correlation groups is identified visually at about $1050 \mathrm{~mm} / \mathrm{yr}$ MAP (indicated by an arrow symbol in Figure 4a). We refer to all the basins with a $M A P$ lower than $1050 \mathrm{~mm} / \mathrm{yr}$ as group A and the rest as group B.

We quantify the correlation with the non parametric Kendall's $\tau_{k}$. The null hypothesis is of no correlation among the two measured variables. We 
reject the null hypothesis when the $p$-value (a measure of the likelihood of the null hypothesis) is less than a significance level of 0.05 . Both trends are significant (group A: $\tau_{k}=-0.423, p=1.4773 e-06$, group B: $\tau_{k}=0.246$, $p=0.03$ ) (Figure 4 $4 \mathrm{~b}$ ) and agree with the results of Collins \& Bras (2010) and previous observational studies (Gregory \& Walling, 1968; Melton, 1957 Abrahams, 1972a; Abrahams \& Ponczynski, 1984; Moglen et al., 1998), in semi-arid (group A) and humid environments (group B).

Correlation between $D_{d d}$ and runoff intensity $(I)(\mathrm{mm} / \mathrm{hr})$ quantified with the non parametric Kendall's $\tau_{k}$ shows no significant correlation $\left(\tau_{k}:-0.0323\right.$, $p=0.69$ ) (Figure S4(a) in the Supplementary Information). Same result is obtained when analyzing group A and group B separately (Figure S4(b)); (Group A: $\left(\tau_{k}:-0.00179, p=0.99\right)$; Group B: $\left(\tau_{k}:-0.00741, p=0.98\right)$ ).

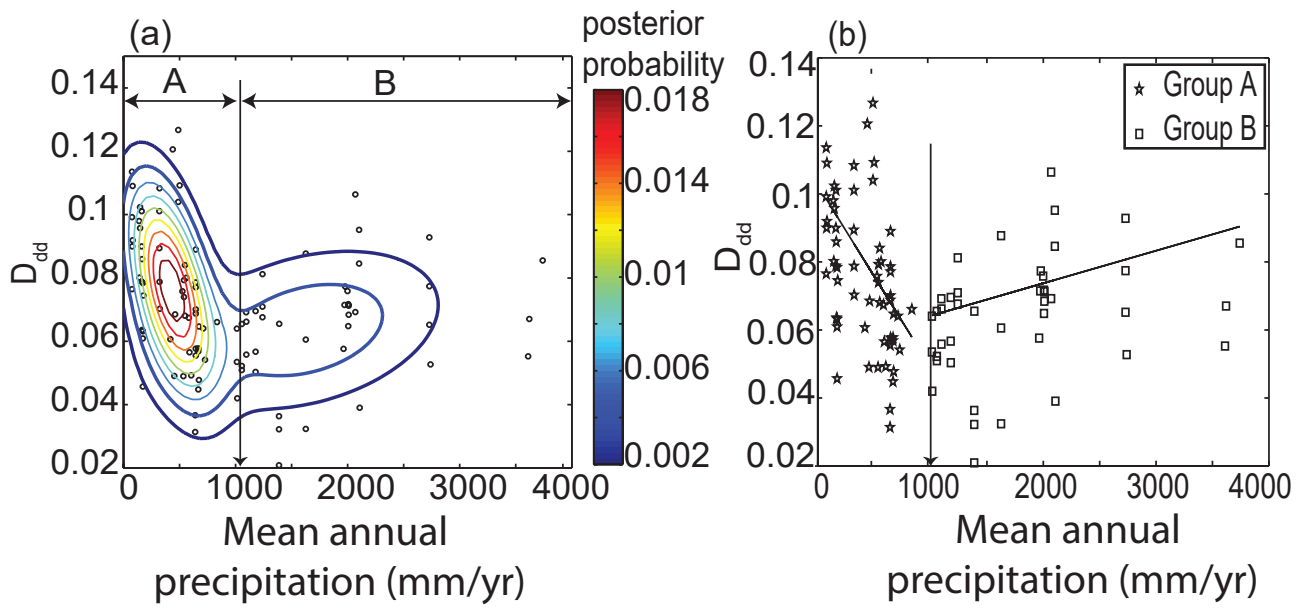

Figure 4: Confirming Melton's hypothesis using high resolution data. (a) Correlation analysis between $D_{d d}$ and $M A P$ with a Gaussian mixture model. The colors on the contours are estimates showing posterior probabilities that indicate the probability of each point to belong to a cluster. All datasets that have less than $1050 \mathrm{~mm} / \mathrm{yr}$ of $M A P$ are labeled as group A, while all other datasets are labeled as group B. (b) The correlation changes from negative in group A to positive in group B. Both trends are significant (group $\mathrm{A}: \tau_{k}=-0.423, p=1.4773 e-06$, group $\left.\mathrm{B}: \tau_{k}=0.246, p=0.030\right)$. The non parameteric Theil-Sen linear trend line for each group is also shown for illustration. For group A the slope of the trend line is $-5.344 \mathrm{e}-05(p=1.1943 e-05)$ and for group B is $9.582 \mathrm{e}-06$ $(p=0.01)$.

\subsection{Soil parameters, relief, and vegetation cover as a function of climate}

First we analyze the variation in $T H I C K$ and $A W C$ with increasing $M A P$ for the entire USA (Figure 5a,b). The values of THICK and $A W C$ reported 
in the STATSGO database for each rock unit polygon as rasters were resampled at $800 \mathrm{~m}$ spatial resolution to match the spatial resolution of $M A P$ obtained from the PRISM climate dataset. The data were then binned into 75 regularly spaced bins in $M A P$ and for each bin the median and standard deviation in THICK and $A W C$ were estimated and plotted. Two change points and three distinct zones (T1, T2, and T3) can be detected (Figure 5 a). In zone T1 (arid landscapes with $M A P<300 \mathrm{~mm} / \mathrm{yr}$ ) the median soil thickness gradually decreases with increasing $M A P\left(\tau_{k}:-0.799, p=2.7358 e-09\right)$. In semi-arid and sub-humid landscapes (T2: $300<M A P<1700 \mathrm{~mm} / \mathrm{yr}$ ) the correlation is positive and median soil thickness increases with $M A P$ $\left(\tau_{k}: 0.892, p=<2.22 e-16\right)$. In very humid landscapes (T3: $M A P>$ $1700 \mathrm{~mm} / \mathrm{yr})$ the correlation remains positive $\left(\tau_{k}: 0.4, p=0.015\right)$. A sharp transition in median soil thickness is observed between zones T2 and T3. Significant amount of variation in soil thickness is observed throughout the range of $M A P$.

Soil thickness and climate determine the amount of water that is available for vegetation at any given location. The analysis of $A W C$ and $M A P$ for the entire USA (Figure 5b) shows that the correlation between these two variables transitions from positive (AWC1: $\tau_{k}=0.801, p=<2.22 e-16$ ) to negative (AWC2: $\left.\tau_{k}=-0.635, p=1.4297 e-06\right)$ with increasing $M A P$. The transition between positive and negative correlation occurs at a $M A P$ of $1050 \mathrm{~mm} / \mathrm{yr}$ (visually identified from Figure 5b). 

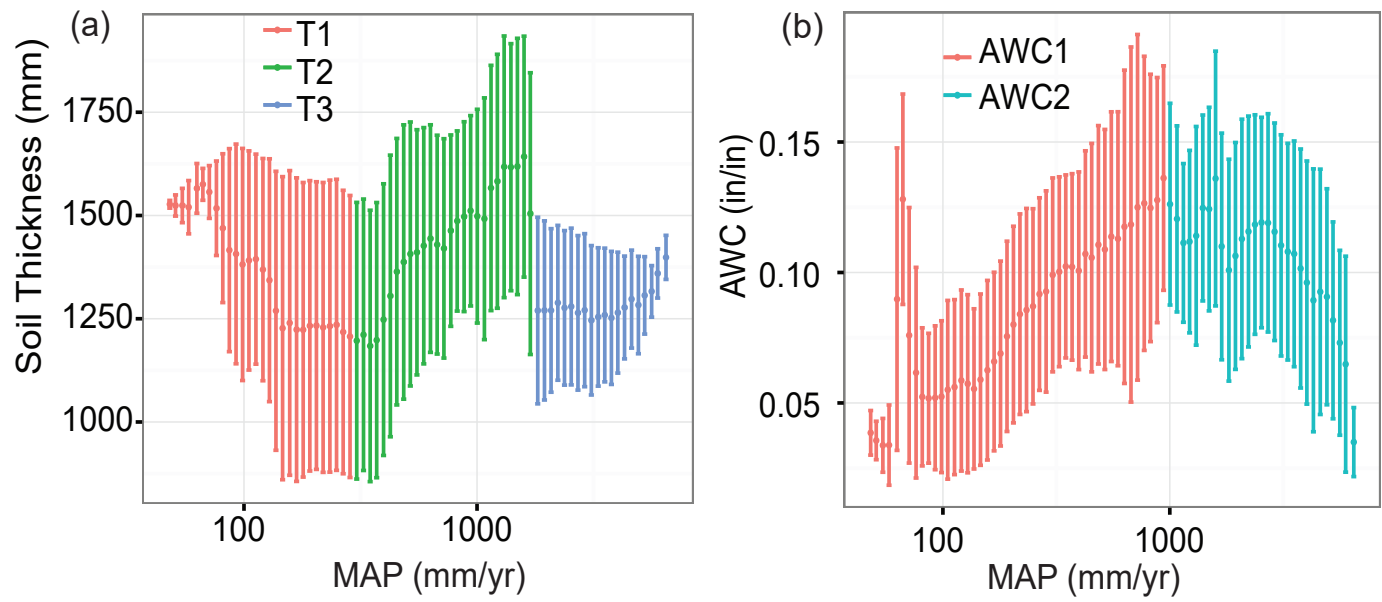

Figure 5: Change in soil thickness $(T H I C K)$ and available water capacity $(A W C)$ as a function of MAP. (a) Variation of soil thickness $(T H I C K)(\mathrm{mm})$ with $M A P(\mathrm{~mm} / \mathrm{yr})$ for the entire USA. Three different groups are identified visually from the plot (T1, T2, T3). (b) Variation of available water capacity $(A W C)$ (in/in) with $M A P(\mathrm{~mm} / \mathrm{yr})$ for the entire USA. Two different groups are identified visually from the plot (AWC1, AWC2). Data are binned into regularly spaced bins in $M A P$ (see text for further discussion).

We perform a similar analysis on relief $R$ and vegetation cover $V_{\text {cov }}$ only for the 101 lidar datasets as the estimation of $V_{\text {cov }}$ requires the availability of HRT data (Figure 6). The data shows that in general higher topographic relief is associated with increasing MAP (Figure 6a). The second order polynomial fit to the data is significant $(p=4.899 e-10)$. Vegetation cover $\left(V_{\text {cov }}\right)$ increases gradually with increasing $M A P$ until about $2500 \mathrm{~mm} / \mathrm{yr}$ and then appears to decrease (second order polynomial fit: $p<2.2 e-16$ ), although few data points are available for MAP above $3000 \mathrm{~mm} / \mathrm{yr}$. 

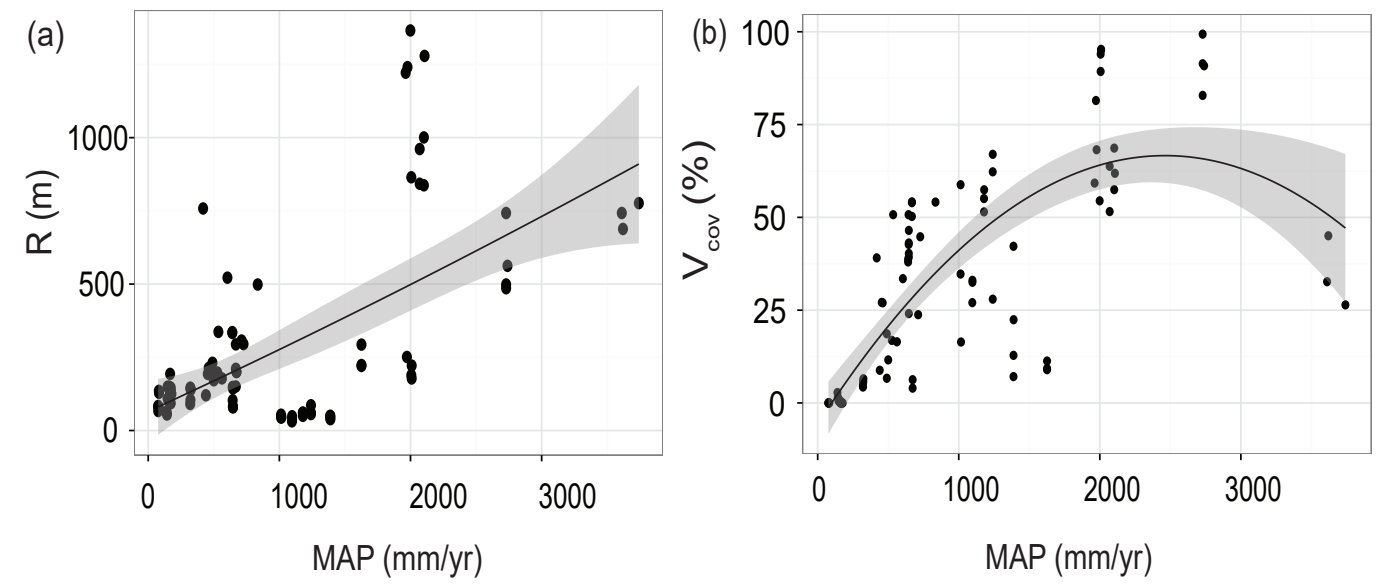

Figure 6: Relief and vegetation cover versus $M A P$. (a) Variation of relief $R(\mathrm{~m})$ with $M A P(\mathrm{~mm} / \mathrm{yr})$ for the lidar datasets. The solid lines represent a second order polynomial fit $(p=4.899 e-10)$. (b) Plot of vegetation cover $\left(V_{\text {cov }}\right)(\%)$ with $M A P(\mathrm{~mm} / \mathrm{yr})$ for the lidar datasets. The predicted second order relationship betweeen $V_{\text {cov }}$ and $M A P$ is significant $(p \leq 2.2 e-16)$. The shaded region in grey around the solid lines represents the $95 \%$ confidence interval.

\subsection{Correlation analysis of $D_{d d}$ and soil parameters}

The analysis of $D_{d d}$ and soil thickness (THICK) shows no significant correlation (group A: $\tau_{k}=-0.0719, p=0.43$, group B: $\tau_{k}=-0.185, p=0.11$; Figure S5(a) in supplementary information). A similar result is obtained from the analysis of $D_{d d}$ and $A W C$ (group A: $\tau_{k}=-0.145, p=0.12$, group B: $\tau_{k}=$ $-0.098, p=0.41$; Figure S5(b) in supplementary information)). Inadequate representation of $A W C$ and $T H I C K$ at comparable scales to $D_{d d}$ could be one of the reasons for the lack of statistical significance.

\subsection{Correlation between $D_{d d}$ and relief}

The relief for each basin is measured as the maximum elevation above the basin outlet. In arid and semi-arid environments (group A) the correlation between topographic relief $R$ and $D_{d d}$ is barely significant $\left(\tau_{k}:-0.179, p=\right.$ 0.04 ), while it is strong and positive in humid environments (group B; $\tau_{k}$ : $0.312, p=0.005$; Figure $7 \mathrm{a}$ ).

Without considering the regional climate, we identify three subgroups of landscapes (R1, R2, R3) (Figure 7b) by using a Gaussian mixture model for $D_{d d}$ and $R$. The first transition point between positive and negative 
correlation is observed at a relief of $\approx 140 \mathrm{~m}$ (indicated by a solid arrow in Figure $7 \mathrm{~b}$ ), while the second transition from negative to positive correlation is observed at a relief of $\approx 500 \mathrm{~m}$ (indicated by a solid arrow in Figure $7 \mathrm{~b}$ ). Group R1 shows positive correlation $\left(\tau_{k}: 0.368, p=0.0009\right)$ while group R2 shows negative correlation $\left(\tau_{k}:-0.315, p=0.008\right)$, both statistically significant, while the correlation in group R3 is not statistically significant $\left(\tau_{k}: 0.209, p=0.27\right)$ (Figure $7 c$ ). These trends are consistent with the study of Howard (1997) in which a change in correlation between $D_{d d}$ and $R$ was reported from positive to negative with increasing relief in the badlands on the Colorado Plateau (USA). 


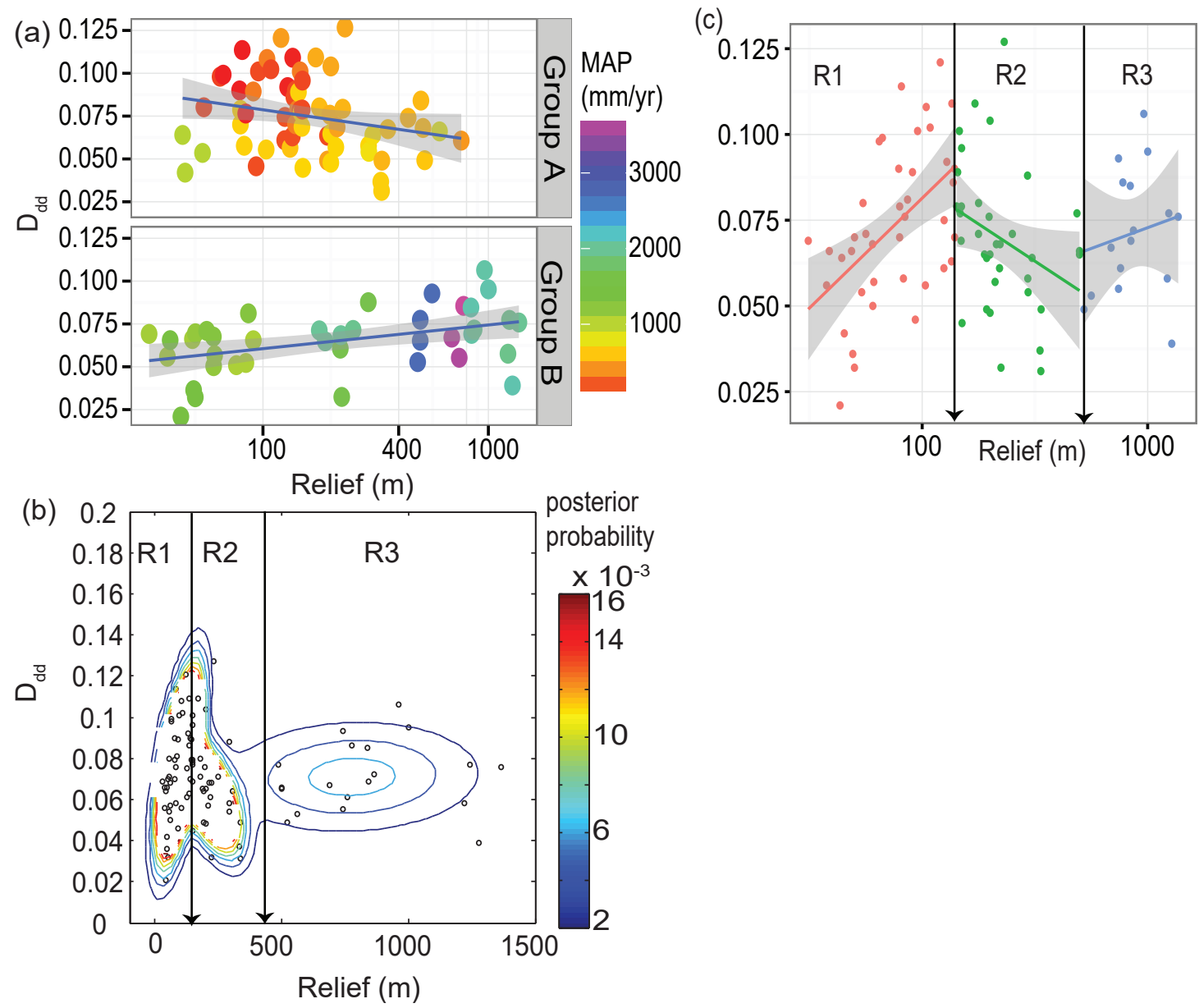

Figure 7: Correlation analysis of $D_{d d}$ and relief. (a) Plot of relief $R(\mathrm{~m})$ above the basin outlet and $D_{d d}$ for groups A and B. The solid line represents a linear relationship between $D_{d d}$ and $R$ (group A: $p=0.03$; group B: $p=0.03$ ). (b) Gaussian mixture model applied to $D_{d d}$ and $R$. Datasets with $R<140 m$ are labeled as R1, $140 m<R<400 m$ as R2, and $R>400 \mathrm{~m}$ as R3. Solid arrows indicate the visually identified transition points. (c) Scatterplot of $D_{d d}$ and $R$ for the three different groups (R1, R2, and R3). Correlations in $\mathrm{R} 1$ and R2 are statistically significant, while correlation in R3 is not. Solid lines represent the linear relation between $D_{d d}$ and $R$ (R1: $p=0.003$; R2: $p=0.08 ; \mathrm{R} 3: p=0.78$ ). Shaded regions in grey represent $95 \%$ confidence intervals. 
4.5. Changes in soil thickness, available water capacity, and vegetation cover with relief

Correlations between THICK, AWC, and $V_{\text {cov }}$ with topographic relief $R$ are analyzed for the three sub groups R1, R2, and R3 (Figure S6 (a)). Soil thickness first decreases with increasing $R$ for low and medium relief landscapes (group $\mathrm{R} 1 ; \tau_{k}:-0.289, p=0.008$ ), while in moderate relief landscapes no significant correlation is observed (group R2: $\tau_{k}=0.0461, p=0.70$ ). Very high relief landscapes show positive correlation between soil thickness and topographic relief (group R3: $\tau_{k}=-0.289, p=0.008$ ).

$A W C$ shows negative correlation with $R$ in low and medium relief landscapes (group R1: $\tau_{k}:-0.451, p=3.9083 e-05$ ) while the correlation in moderate (group R2: $\tau_{k}=0.172, p=0.14$ ) and high relief landscapes (group R3: $\left.\tau_{k}=-0.133, p=0.50\right)$ is not significant (Figure S6 (b)). Similarly, $V_{\text {cov }}$ shows negative correlation with $R$ in group $\mathrm{R} 1\left(\tau_{k}=-0.324, p=0.004\right)$ and positive correlation in group $\mathrm{R} 2\left(\tau_{k}=0.316, p=0.007\right)$ and group R3 (not significant: $\tau_{k}=0.126, p=0.52$ ) (Figure S6 (c)).

\subsection{Correlation between $D_{d d}$ and vegetation cover}

Two opposite correlations are observed between $D_{d d}$ and $V_{\text {cov }}$ (Figure 8a) when the basins are subdivided based on climate. In group A the correlation between $D_{d d}$ and $V_{\text {cov }}$ is negative $\left(\tau_{k}:-0.333, p=0.0004\right)$, while in group B it is weakly positive $\left(\tau_{k}: 0.241, p=0.04\right)$. The analysis of $D_{d d}$ and $V_{c o v}$ for the whole range shows that $D_{d d}$ decreases with increasing $V_{\text {cov }}\left(\tau_{k}:-0.186\right.$, $p=0.009 ;$ Figure $8 \mathrm{~b})$.

While the maximum vegetation cover observed in arid and semiarid environments (group $\mathrm{A}$ ) does not exceed $\approx 55 \%$ with a mean canopy height of $\approx 3.51 \mathrm{~m}$, a wider range of vegetation cover is observed in humid environments (group $\mathrm{B} ; \approx 1 \%-99 \%$ ) with a mean canopy height $\approx 12.1 \mathrm{~m}$ (Figure 8c).

We group vegetation by type into barren lands, grasslands, shrubs, broad leaf forests, needle leaf forests, and mixed forests and analyze the variation in $D_{d d}$ as boxplots for each land cover type (Figure 8d). Except for barren lands, the median $D_{d d}$ remains fairly constant for each land cover type. We note that the sample size for three of the vegetation types analyzed is small. 
(a)

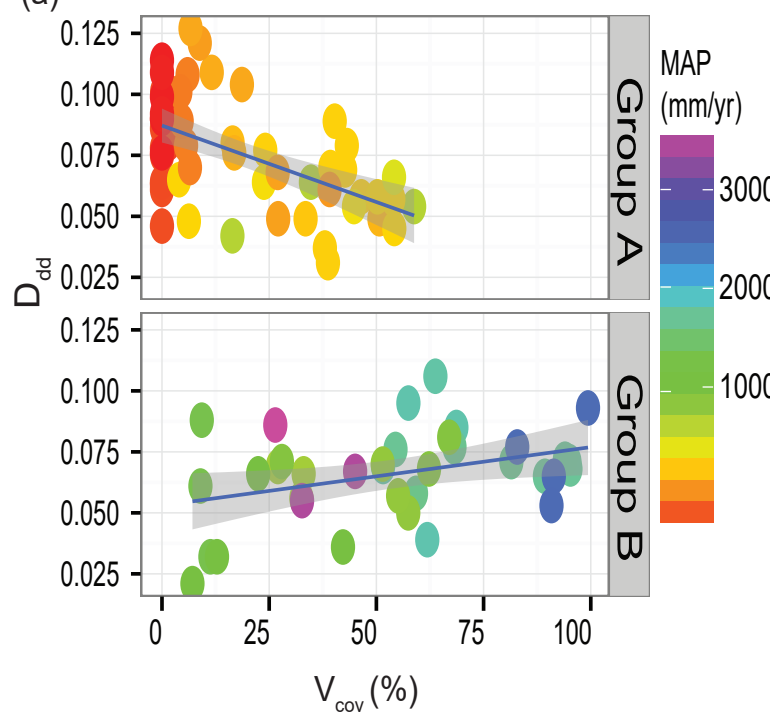

(b)

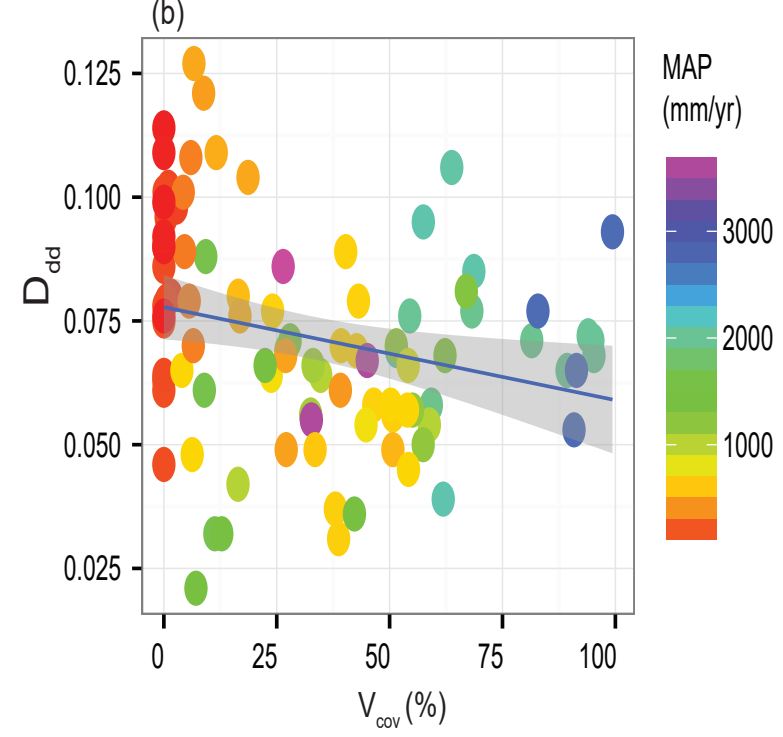

(c)

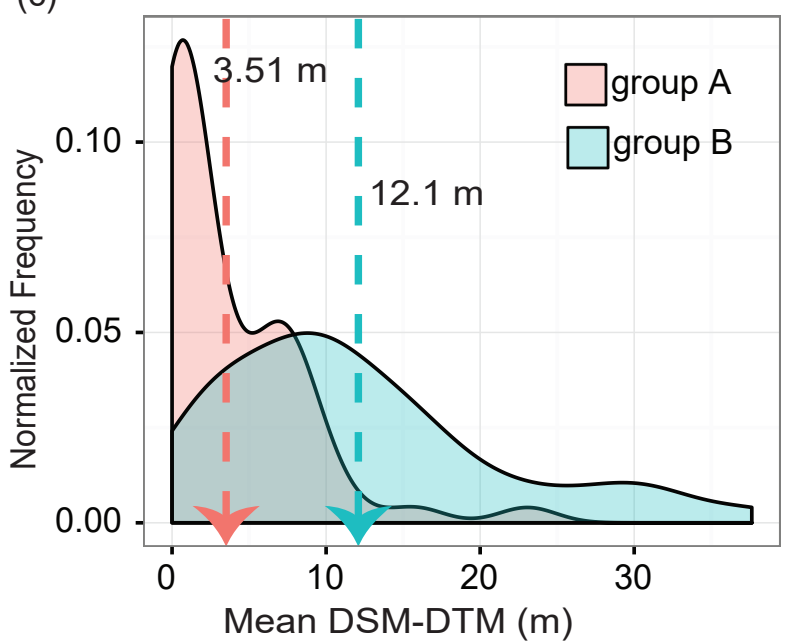

(d)

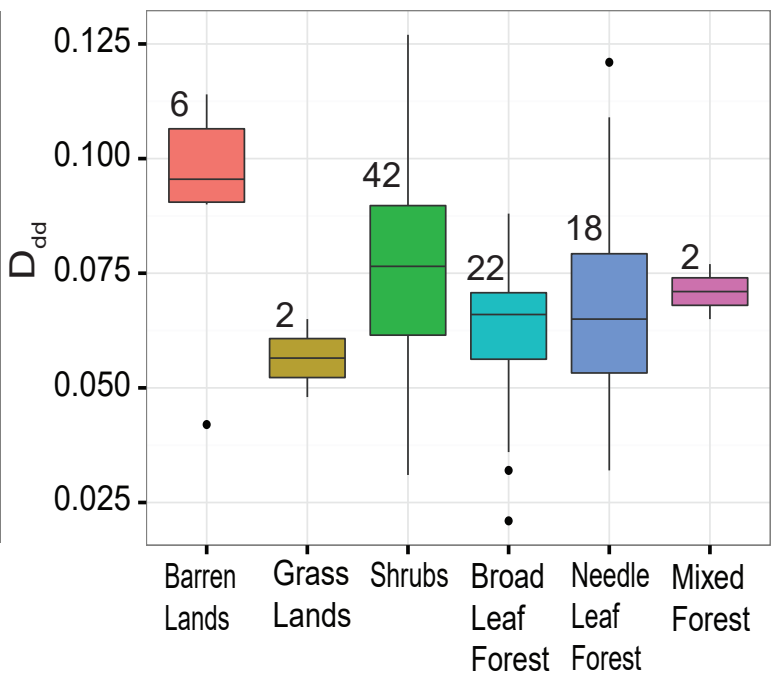

increasing vegetation cover $(\%)$

Figure 8: Correlation of $D_{d d}$ and vegetation cover. (a) $D_{d d}$ and vegetation cover $V_{\text {cov }}(\%)$ for group A and B. The solid line represents the linear relationship between $D_{d d}$ and $V_{c o v}$ (Group A: $p=7.852 e-06$, Group B: $p=0.023$ ). 
Figure 8: (Continued..) (b) $D_{d d}$ and vegetation cover $V_{\text {cov }}(\%)$ for the whole dataset $(p=0.01)$. (c) Mean height distribution (DSM-DTM) for each group with sample means (dotted lines). Group A mean height is $3.51 \mathrm{~m}$ and group B mean height is $12.1 \mathrm{~m}$. (d) $D_{d d}$ variation within each class of vegetation type arranged by increasing $V_{c o v}$. The numbers indicate the sample size of each group.

\subsection{Correlation between $D_{d d}$ and lithology}

The analysis of $D_{d d}$ and rock type arranged in increasing order of mean $U C S$ (Figure 9) shows that $D_{d d}$ is lowest for the unconsolidated sediments (sand and clay) compared to other rock types. Overall $D_{d d}$ decreases with increasing uniaxial compressive rock strength, however, the small sample size of three of the rock types analyzed likely affects the results.

We analyze the relationship between $D_{d d}$ and rock strength after grouping rock types in three groups: sand and clay (group L1: $U C S<0.25 \mathrm{MPa}$ ), strong rock basins (group L2: $50 \mathrm{MPa}<U C S<100 \mathrm{MPa}$ ), and very strong rock basins (group L3: $100 \mathrm{MPa}<U C S<250 \mathrm{MPa}$ ) (Figure S7). No significant correlation between $D_{d d}$ and $U C S$ is observed in group L1 (less than 12 sample points) and L2 $\left(\tau_{k}: 0.106, p=0.46\right)$. A weak negative correlation between $D_{d d}$ and $U C S$ is observed in group L3 $\left(\tau_{k}:-0.183, p=0.047\right)$, indicating decreasing $D_{d d}$ with increasing uniaxial compressive strength (as rock hardness increases). The control of lithology $(U C S)$ on $D_{d d}$ is also analyzed within climate groups A and B. Correlations between $D_{d d}$ and $U C S$ are not statistically significant for either group (group A: $\tau_{k}$ : 0.0409, $p=0.66$; group B: $\tau_{k}:-0.0358, p=0.78$; Figure S7). 


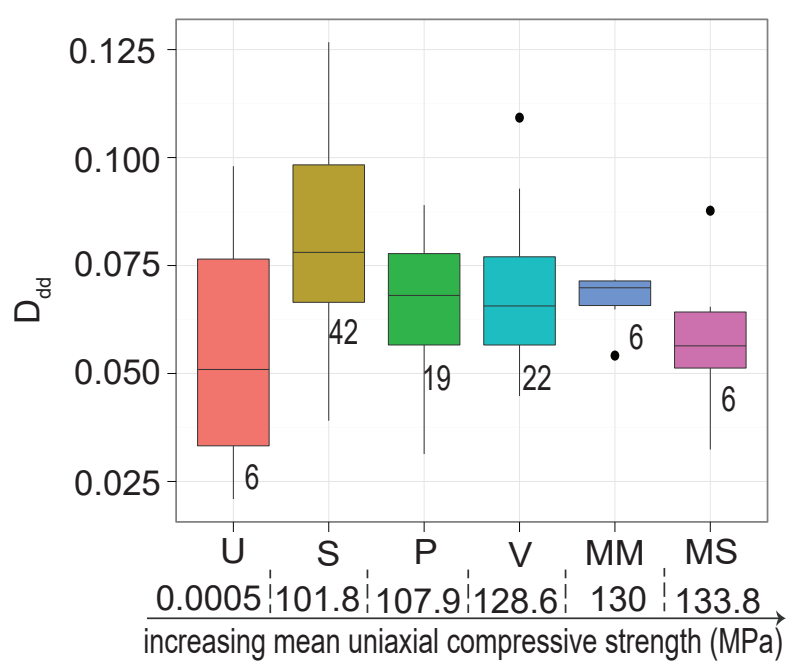

Figure 9: $D_{d d}$ for different rock types arranged by increasing mean uniaxial compressive strength $(\mathrm{MPa})$. The boxplot shows the first and third quartiles. The number of samples for each group are indicated. The rock types are U- Unconsolidated sediment, S- Sedimentary rock, P- Plutonic rock, V- Volcanic rock, MM- Metamorphic rock, MSMetasedimentary rock.

\section{Discussion}

The analysis presented here revisits and supports the hypothesis of Melton (1957) that climate, topography, vegetation, and lithology affect drainage density. We tested this hypothesis over natural landscapes across a wide range of $M A P$ for which HRT data are available.

Objective extraction of drainage density is essential in hydro-geomorphic analyses such as the one here performed. Our proposed dimensionless drainage density $\left(D_{d d}\right)$ metric provides a simple and elegant way to estimate the extent of channelization in natural landscapes using HRT data. $D_{d d}$ has the advantage of eliminating the need for channel network extraction. Furthermore, the scaling analysis of $D_{d d}$ shows weak dependence on the input DTM resolution compared to the classic dimensional drainage density metric $\left(D_{g}\right)$, allowing the computation of $D_{d d}$ from coarser resolution DEMs with reduced bias. We also showed that a power law exists between the dimensionless drainage density and the input DEM resolution, offering the opportunity to estimate drainage density at finer resolutions based on a coarser DEM. 
The current study offers insight into the role of climate, soil parameters, topographic relief, vegetation, and lithology on the extent of landscape dissection. Previous studies have either shown an inverse relationship between $D_{d}$ and MAP (Melton, 1957) or a non-monotonic relation in which drainage density decreases with $M A P$ in arid and semiarid climates and increases in humid environments (Gregory \& Walling, 1968; Collins \& Bras, 2010). The Gaussian mixture model used in our analysis identifies two subgroups of landscapes; in group A basins (arid environments) the correlation between $D_{d d}$ and MAP is negative, while in group B basins (humid environments) it is positive. The transition between the two groups occurs around MAP of $1000-1100 \mathrm{~mm} / \mathrm{yr}$ and coincides with transitions in soil thickness and available water capacity. In group A (arid and semi-arid environments) the increasing thickness of soil layers and available water capacity with $M A P$ promote dense plant cover and reduce erosion due to runoff, decreasing the overall drainage density. In humid regions (group B) the available water capacity decreases accompanied by a sudden drop in soil thickness by $\approx 400$ $\mathrm{mm}$, which causes a gradual decrease in vegetation cover (Figure 6b) and boosts erosion due to overland flow resulting in increased drainage density. Changes in soil properties with varying climate conditions have also been observed by Chadwick et al. (2003) for catchments in Hawaii, where a dominant threshold in saturation of base cation was predicted at $M A P \approx 1400$ $\mathrm{mm} / \mathrm{yr}$. Although our analysis did not consider soil chemical properties, we observed their effect in the correlation of $A W C$ and THICK with MAP. By using a Gaussian mixture model we recognized similar transition zones to those observed by Chadwick et al. (2003).

The results obtained from the analysis of $D_{d d}$ and $M A P$ are similar to the results of Collins \& Bras (2010) for steady state modeled landscapes and field measurements from northern Colorado. Their analysis showed a transition in correlation at about $300 \mathrm{~mm} / \mathrm{yr}$ but was restricted to soil mantled water limited equilibrium landscapes characterized by low-medium relief. This difference may explain the mismatch between the transition point in our study and Collins \& Bras (2010). Furthermore Collins \& Bras (2010) noted that the identified transition point was likely too low.

The analysis of natural landscapes offers valuable insights to inform landscape evolution models and provides results from landscapes that are not at steady state. For example, the correlation between $D_{d d}$ and various controlling factors change (only some are significant trends) upon decoupling the analysis from the effect of $M A P$. This result highlights the extent to 
which individual factors control landscape dissection under similar climatic regimes. Similarly, the strong influence of $M A P$ over $A W C$ and soil thickness allows ranges of soil thickness and soil moisture to be identified within similar climatic regimes. Such estimates may be helpful in soil production and vegetation growth models.

Previous studies based on slope models by Kirkby $(1978,1992)$ predicted that $D_{d}$ increases in humid climates with increasing relief $R$, while it is independent of $R$ in semi-arid environments. Oguchi (1997b), instead, found an inverse relationship between $D_{d}$ and $R$ for mountainous terrain in Japan prone to landsliding and other mass wasting processes. In this study, $D_{d d}$ shows weak negative correlation with $R$ in arid and semi-arid environments while it shows strong positive correlation in humid environments.

Geomorphic transport laws used in landscape evolution models predict a power law relationship between $D_{d}$ and $R\left(D \propto R^{-\xi}\right)$ such that the correlation between the variables is positive in creep dominated landscapes and negative in landslide prone ones (Tucker \& Bras, 1998). Similar behavior emerges in our analysis as indicated by the Gaussian mixture model applied to $D_{d d}$ and $R$ (Figure $7 \mathrm{k}$ ). We observe that for low - medium relief landscapes (group R1) soil thickness, $A W C$, and $V_{\text {cov }}$ decrease with increasing relief resulting in increased landscape dissection in the basins. At around $R \approx 140 \mathrm{~m}$ the correlation between $D_{d d}$ and $R$ changes from positive to negative as the increase in plant cover aided by thick soil layers and high $A W C$ reduces drainage density (Figure $7 \mathrm{c}$ for group R2). No significant correlation between $D_{d d}$ and $R$ is observed for group R3. Howard (1997) observed a similar change in correlation between $D_{d d}$ and relative relief ratio and suggested that the transition from positive to negative correlation is due to a change from diffusion mass wasting to threshold dominated mass wasting processes. The results presented here may indicate dominant process signatures. Field observations are needed to confirm these results.

Our analysis shows that vegetation cover changes with $M A P$; canopy density increases with increasing $M A P$ until $2000 \mathrm{~mm} / \mathrm{yr}$ and then starts decreasing. As we decouple the climatic signature and look at correlations between $D_{d d}$ and $V_{c o v}$ within each group A and B, we observe opposite trends (Figure 8a). Istanbulluoglu \& Bras (2005) observed similar behaviors and reported that for equilibrium landscapes with relatively moderate ratio of uplift to diffusivity $\left(U_{*}\right)$ vegetation controlled erosion processes at channel heads unlike landscapes with high and low $U_{*}$ values. Negative correlation between $D_{d d}$ and $V_{\text {cov }}$ implies that $V_{\text {cov }}$ increases the threshold for channel 
initiation resulting in decreasing drainage density. A positive correlation between $D_{d d}$ and $V_{c o v}$ is difficult to understand (weakly significant in our analysis). As suggested by other field based studies (Dunne et al., 2010, Jahn, 1991), this behavior can occur when landscapes are experiencing constant rates of uplift and dense vegetation cover is hindering hillslope diffusivity (Istanbulluoglu \& Bras, 2005). To keep up with increasing uplift rates and decreasing hillslope diffusivity (reduced by increasing vegetation cover), $D_{d}$ will gradually increase. We observe that mean canopy height for group B is 4 times higher than group $\mathrm{A}$ and the average canopy cover is also higher in group B than group A (Figure 8k) which might decrease the hillslope diffusivity in these basins. Such process signatures are not seen when group $\mathrm{A}$ and $\mathrm{B}$ are combined into a single dataset. In this case, $D_{d d}$ decreases with increasing $V_{\text {cov }}$ as observed by Melton (1957).

The dominant plant communities observed in the 101 subbasins are shrubs, grasslands, broad leaf deciduous trees, needle leaf and mixed forests (Figure 8d). Only basins with barren land had significantly different median $D_{d d}$, while all the other vegetation types had similar median $D_{d d}$ values. These results may be influenced by the uneven sample size for each vegetation type analyzed.

Most basins included in our study have lithology dominated by strong rocks (Figures 9 and $\mathrm{S} 7$ ). Our results indicate that $D_{d}$ spans over variable yet similar ranges for the rock types (Figure 9). Mueller \& Pitlick (2013) showed similar trends for various rock types in the Northern Rocky Mountains, USA. Day (1980) observed in six small rural catchments in Southern New England that drainage density was highest for sedimentary rocks compared to granite rocks. Our results also show that $D_{d d}$ is relatively higher for sedimentary rocks compared to other groups.

No significant correlation between $D_{d}$ and $U C S$ is observed when the signature of climate is removed (Figure S7 (b)). Similarly, no significant correlation is observed when basins are clustered by rock strength except for a weak correlation in group L3 (very strong rocks). Since most of the rocks in the areas analyzed are either strong rocks or very strong rocks, our sample choice may prevent us from observing any dominant trend. There is significant spread around the mean uniaxial compressive strength used for each rock type preventing the mean from representing appropriately the rock strength in the basin. The lack of any significant correlation across different rock types may also be due to the coarse resolution of the lithology datasets. The same analysis repeated on a larger dataset may highlight 
significant relationships between $D_{d}$ and $U C S$. Based on our results, climate and vegetation appear to have a more dominant impact on drainage density than rock strength and geology.

Our statistical analysis has consisted of the exploration of one to one relationships among $D_{d d}$ and climate and other factors and of these factors with each other. The results of preliminary multivariate statistical analyses (correlation analysis and Principal Component Analysis; Figure S1, S2, and S3 in supplementary information ) supported the choice of investigating multiple one-to-one relationships. The first PC component (PC1), for example, explained only $40 \%$ of the variance. Future work will include further multivariate statistical analysis of these datasets. In addition, while the current study has looked at fairly small non urbanized basins, future work could include larger basins representative of more rock types. Urbanized catchments could also be analyzed to test the performance of the dimensionless drainage density metric.

\section{Conclusions}

In this work we proposed a dimensionless drainage density metric $\left(D_{d d}\right)$ based on the number of likely channelized pixels in a basin. The proposed metric $D_{d d}$ is less dependent on the input DTM resolution when compared to the classic drainage density metric $\left(D_{g}\right)$. We measured $D_{d d}$ on HRT data across the USA and analyzed its correlation with climate, topography, vegetation, and lithology. Two subgroups of landscapes are identified by a Gaussian mixture model of $D_{d d}$ and mean annual precipitation $M A P$ (group A: arid and semi-arid; group B: humid environments). The analysis of $D_{d d}$ and $M A P$ shows a transition from negative to positive correlation at MAP 1000-1100 $\mathrm{mm} / \mathrm{yr}$. The changeover range coincides with variations in vegetation cover, soil thickness, and available water capacity.

$D_{d d}$ shows weak negative correlation with relief in arid and semi-arid environments and strong positive correlation in humid environments. The analysis of $D_{d d}$ and vegetation cover shows that $D_{d d}$ increases with decreasing vegetation cover. No significant correlation is observed between rock characteristics (lithology and rock strength) and $D_{d d}$ in the analyzed data, although the lack of correlation may be due to our sample choice.

Our results capture the effect of runoff, vegetation, soil thickness, available water capacity, topographic relief, and rock strength on drainage density across varying $M A P$ regimes in natural landscapes. 


\section{Acknowledgments}

This material is based on work supported by the National Science Foundation (grants GSS/BCS-1063228, CAREER/EAR-1350336 to PP and GSS/BCS1063228 to CPS). Support for HS from the National Science Foundation and USGS John Wesley Powell Center for Analysis and Synthesis as Fellow of the Powell Center Working Group on High Resolution Topography is gratefully acknowledged. All the input datasets and the sub basins analyzed within each dataset are available for download at https://sites.google.com/site/geonethome/.

\section{References}

Abrahams, A. D. (1972a). Drainage densities and sediment yields in eastern Australia. Australian Geographical Studies, 10, 19-41.

Abrahams, A. D. (1972b). Environmental constraints on the substitution of space for time in the study of natural channel networks. Geological Society of America Bulletin, 83, 1523-1530.

Abrahams, A. D. (1984). Channel networks: A geomorphological perspective. Water Resources Research, 20, 161-168.

Abrahams, A. D., \& Ponczynski, J. J. (1984). Drainage density in relation to precipitation intensity in the U.S.A. Journal of Hydrology, 75, 383-388.

Carlston, C. W. (1963). Drainage density and streamflow. US Govt. Print. Off.

Chadwick, O. A., Gavenda, R. T., Kelly, E. F., Ziegler, K., Olson, C. G., Elliott, W., \& Hendricks, D. M. (2003). The impact of climate on the biogeochemical functioning of volcanic soils. Chemical Geology, 202, 195 - 223. URL: http://www.sciencedirect.com/science/article/ pii/S0009254103002456. doi:http://dx.doi.org/10.1016/j.chemgeo. 2002.09.001. Controls on Chemical Weathering.

Chadwick, O. A., Roering, J. J., Heimsath, A. M., Levick, S. R., Asner, G. P., \& Khomo, L. (2013). Shaping post-orogenic landscapes by climate and chemical weathering. Geology, . URL: http://geology.gsapubs.org/content/ early/2013/09/06/G34721.1.abstract. doi:10.1130/G34721.1. arXiv:http://geology.gsapubs.org/content/early/2013/09/06/G34721.1.full.pdf+htm] 
Chorley, R. J. (1957). Climate and morphometry. Journal of Geology, 65, 628-638. doi:http://www.jstor.org/stable/30058827.

Clark, M. L., Roberts, D. A., Ewel, J. J., \& Clark, D. B. (2011). Estimation of tropical rain forest aboveground biomass with small-footprint lidar and hyperspectral sensors. Remote Sensing of Environment, 115, 2931

- 2942. URL: http://www.sciencedirect.com/science/article/pii/ S0034425711001404. doi:http://dx.doi.org/10.1016/j.rse.2010.08. 029. \{DESDynI\} VEG-3D Special Issue.

Collins, D. B. G., \& Bras, R. L. (2010). Climatic and ecological controls of equilibrium drainage density, relief, and channel concavity in dry lands. Water Resources Research, 46, W04508. doi:10.1029/2009WR008615.

Daniel, J. R. K. (1981). Drainage density as an index of climatic geomorphology. Journal of Hydrology, 50, 147-154.

Day, D. G. (1980). Lithologic controls of drainage density: A study of six small rural catchments in new england, n.s.w. $\{C A T E N A\}$, 7, 339

- 351. URL: http://www.sciencedirect.com/science/article/pii/

0341816280900181. doi:http://dx.doi.org/10.1016/0341-8162(80) 90018-1.

Dunne, T., Malmon, D. V., \& Mudd, S. M. (2010). A rain splash transport equation assimilating field and laboratory measurements. Journal of Geophysical Research: Earth Surface (2003-2012), 115.

Gabet, E. J., \& Mudd, S. M. (2010). Bedrock erosion by root fracture and tree throw: A coupled biogeomorphic model to explore the humped soil production function and the persistence of hillslope soils. Journal of Geophysical Research: Earth Surface, 115, n/a-n/a. URL: http://dx. doi.org/10.1029/2009JF001526. doi:10.1029/2009JF001526.

Gabet, E. J., Reichman, O. J., \& Seabloom, E. W. (2003). The effects of bioturbation on soil processes and sediment transport. Annual Review of Earth and Planetary Sciences, 31, 249-273.

Glennie, C. L., Carter, W. E., Shrestha, R. L., \& Dietrich, W. E. (2013). Geodetic imaging with airborne lidar: the earth's surface revealed. Reports on Progress in Physics, 76, 086801. URL: http://stacks.iop.org/ $0034-4885 / 76 / i=8 / a=086801$. doi $10.1088 / 0034-4885 / 76 / 8 / 086801$. 
Goulden, T., Hopkinson, C., Jamieson, R., \& Sterling, S. (2014). Sensitivity of watershed attributes to spatial resolution and interpolation method of lidar dems in three distinct landscapes. Water Resources Research, 50, 1908-1927. URL: http://dx.doi.org/10.1002/2013WR013846, doi:10. 1002/2013WR013846.

Gregory, K. J., \& Walling, D. E. (1968). The variation of drainage density within a catchment. Hydrological Sciences Journal, 13, 61-68. doi:10. 1080/02626666809493583.

Harpold, A. A., Marshall, J. A., Lyon, S. W., Barnhart, T. B., Fisher, B., Donovan, M., Brubaker, K. M., Crosby, C. J., Glenn, N. F., Glennie, C. L., Kirchner, P. B., Lam, N., Mankoff, K. D., McCreight, J. L., Molotch, N. P., Musselman, K. N., Pelletier, J., Russo, T., Sangireddy, H., Sjöberg, Y., Swetnam, T., \& West, N. (2015). Laser vision: lidar as a transformative tool to advance critical zone science. Hydrology and Earth System Sciences Discussions, 12, 1017-1058. URL: http: //www.hydrol-earth-syst-sci-discuss.net/12/1017/2015/, doi:10. 5194/hessd-12-1017-2015.

Horton, R. E. (1932). Drainage-basin characteristics. Transactions, American geophysical union, 13, 350-361. doi:10.1029/TR013i001p00350.

Howard, A. D. (1997). Badland morphology and evolution: Interpretation using a simulation model. Earth Surface Processes and Landforms, 22, $211-227$.

Howard, A. D. (1998). Long profile development of bedrock channels: Interaction of weathering, mass wasting, bed erosion, and sediment transport. In E. E. Wohl, \& K. J. Tinkler (Eds.), Rivers over Rock: Fluvial Processes in Bedrock Channels Geophysical Monograph Series (pp. 297-320). American Geoph. Union.

Hurst, M. D., Mudd, S. M., Yoo, K., Attal, M., \& Walcott, R. (2013). Influence of lithology on hillslope morphology and response to tectonic forcing in the northern sierra nevada of california. Journal of Geophysical Research: Earth Surface, 118, 832-851. URL: http://dx.doi.org/10. 1002/jgrf.20049, doi:10.1002/jgrf.20049. 
Istanbulluoglu, E., \& Bras, R. L. (2005). Vegetation-modulated landscape evolution: Effects of vegetation on landscape processes, drainage density, and topography. Journal of Geophysical Research, 110, F02012. doi:10. 1029/2004JF000249.

Jahn, A. (1991). Slow soil movement in tarfala valley, kebnekaise mountains, swedish lapland. Geografiska Annaler. Series A. Physical Geography, (pp. 93-107).

Kelson, K. I., \& Wells, S. G. (1989). Geologic influences on fluvial hydrology and bedload transport in small mountainous watersheds, northern new

- mexico, usa. Earth surface processes and landforms, 14, 671-690. doi:10. 1002/esp.3290140803.

Kirkby, M. (1978). The stream head as a significant geomorphic threshold. School of Geography, University of Leeds.

Kirkby, M. (1992). Thresholds and instability in stream head hollows: a model of magnitude and frequency for wash processes. School of Geography, University of Leeds.

Lashermes, B. L., Foufoula-Georgiou, E., \& Dietrich, W. E. (2007). Channel network extraction from high resolution topography using wavelets. Geophysical Research Letters, 34, L23S04. doi:10.1029/2007GL031140.

Li, J., \& Wong, D. W. (2010). Effects of $\{$ DEM $\}$ sources on hydrologic applications. Computers, Environment and Urban Systems, 34, 251 - 261. URL: http://www.sciencedirect.com/science/ article/pii/S0198971509000933. doi:http://dx.doi.org/10.1016/j. compenvurbsys.2009.11.002.

Lin, Z., \& Oguchi, T. (2004). Drainage density, slope angle, and relative basin position in japanese bare lands from high-resolution dems. Geomorphology, 63, 159-173.

Luoto, M. (2007). New insights into factors controlling drainage density in subarctic landscapes. Arctic, Antarctic, and Alpine Research, 39, 117-126. doi:10.1657/1523-0430(2007)39[117:NIIFCD]2.0.C0;2.

Madduma Bandara, C. M. (1974). Drainage density and effective precipitation. Journal of Hydrology, 21, 187-190. 
McLachlan, G., \& Peel, D. (2004). Finite mixture models. John Wiley \& Sons.

Melton, M. A. (1957). An analysis of the relations among elements of climate, surface properties, and geomorphology. Technical Report 11 Office of Naval Research Department of Geology, Columbia University.

Moglen, G. E., Eltahir, E. A. B., \& Bras, R. L. (1998). On the sensitivity of drainage density to climate change. Water Resources Research, 34 , 855-862.

Morisawa, M. (1957). Accuracy of determination of stream lengths from topographic maps. Transactions of the American Geophysical Union, 38, 86-88.

Morisawa, M. (1961). Reply to letter by W. J. Schneider, 'A note on the accuracy of drainage densities computed from topographic maps'. Journal of Geophysical Research, 66, 3619. doi:10.1029/JZ066i010p03619.

Mueller, E. R., \& Pitlick, J. (2013). Sediment supply and channel morphology in mountain river systems: 1. relative importance of lithology, topography, and climate. Journal of Geophysical Research: Earth Surface, 118, 2325-

2342. URL: http://dx.doi.org/10.1002/2013JF002843. doi:10.1002/ 2013JF002843.

Nilsson, M. (1996). Estimation of tree heights and stand volume using an airborne lidar system. Remote Sensing of Environment, 56, $1-7$. URL: http://www.sciencedirect.com/ science/article/pii/0034425795002243. doi:http://dx.doi.org/10 . 1016/0034-4257(95)00224-3.

Oguchi, T. (1997a). Drainage density and relative relief in humid steep mountains with frequent slope failure. Earth Surface Processes and Landforms, 22, 107-120. URL: http://dx.doi.org/10.1002/(SICI)

1096-9837(199702) 22:2<107: :AID-ESP680>3.0.CO;2-U. doi:10.1002/ (SICI) 1096-9837(199702) 22:2<107: :AID-ESP680>3.0.CO;2-U.

Oguchi, T. (1997b). Drainage density and relative relief in humid steep mountains with frequent slope failure. Earth Surface Processes and Landforms, 22, 107-120. 
Passalacqua, P., Belmont, P., Staley, D. M., Simley, J. D., Arrowsmith, J. R., Bode, C. A., Crosby, C., DeLong, S. B., Glenn, N. F., Kelly, S. A. et al. (2015). Analyzing high resolution topography for advancing the understanding of mass and energy transfer through landscapes: A review. Earth-Science Reviews, 148, 174-193.

Passalacqua, P., Hillier, J., \& Tarolli, P. (2014). Innovative analysis and use of high-resolution dtms for quantitative interrogation of earth-surface processes. Earth Surface Processes and Landforms, 39, 1400-1403. doi:10. 1002/esp.3616.

Passalacqua, P., Tarolli, P., \& Foufoula-Georgiou, E. (2010a). Testing spacescale methodologies for automatic geomorphic feature extraction from lidar in a complex mountainous landscape. Water Resources Research, 46, W11535. doi:10.1029/2009WR008812.

Passalacqua, P., Trung, T.-D., Foufoula-Georgiou, E., Sapiro, G., \& Dietrich, W. E. (2010b). A geometric framework for channel network extraction from lidar: Nonlinear diffusion and geodesic paths. Journal of Geophysical Research, 115, F01002. doi:10.1029/2009JF001254.

Pelletier, J. D. (2013). A robust, two-parameter method for the extraction of drainage networks from high-resolution digital elevation models (dems): Evaluation using synthetic and real-world dems. Water Resources Research, 49, 75-89. URL: http://dx.doi.org/10.1029/2012WR012452. doi:10.1029/2012WR012452.

Pelletier, J. D., McGuire, L. A., Ash, J. L., Engelder, T. M., Hill, L. E., Leroy, K. W., Orem, C. A., Rosenthal, W. S., Trees, M. A., Rasmussen, C., \& Chorover, J. (2011). Calibration and testing of upland hillslope evolution models in a dated landscape: Banco bonito, new mexico. Journal of Geophysical Research: Earth Surface, 116, n/a-n/a. URL: http://dx. doi.org/10.1029/2011JF001976. doi:10.1029/2011JF001976.

Rodríguez-Iturbe, I., \& Rinaldo, A. (2001). Fractal river basins: chance and self-organization. Cambridge University Press.

Roering, J. J., Almond, P., Tonkin, P., \& McKean, J. (2004). Constraining climatic controls on hillslope dynamics using a coupled model for the transport of soil and tracers: Application to loess-mantled hillslopes, 
south island, new zealand. Journal of Geophysical Research: Earth Surface, 109, n/a-n/a. URL: http://dx.doi.org/10.1029/2003JF000034. doi:10.1029/2003JF000034.

Roering, J. J., Mackey, B. H., Marshall, J. A., Sweeney, K. E., Deligne, N. I., Booth, A. M., Handwerger, A. L., \& Cerovski-Darriau, C. (2013). you are here: Connecting the dots with airborne lidar for geomorphic fieldwork. Geomorphology, 200, 172 - 183. URL: http:// www.sciencedirect.com/science/article/pii/S0169555X13002031. doi:http://dx.doi.org/10.1016/j.geomorph.2013.04.009. The Field Tradition in Geomorphology 43rd Annual Binghamton Geomorphology Symposium, held 21-23 September 2012 in Jackson, Wyoming \{USA\}.

Sangireddy, H., Stark, C. P., Kladzyk, A., \& Paola, P. (2016). Geonet: An open source software for the automatic and objective extraction of channel heads, channel network, and channel morphology from high resolution topography data. Environmental Modelling $\mathcal{E}$ Software, In review, 00-00.

Schneider, W. J. (1961). A note on the accuracy of drainage densities computed from topographic maps. Journal of Geophysical Research, 66, 361703618. doi:10.1029/JZ066i010p03617.

Smith, V. B., David, C. H., Cardenas, M. B., \& Yang, Z.-L. (2013). Climate, river network, and vegetation cover relationships across a climate gradient and their potential for predicting effects of decadal-scale climate change. Journal of Hydrology, 488, 101 - 109. URL: http://www.sciencedirect.com/science/article/ pii/S0022169413001819, doi:http://dx.doi.org/10.1016/j.jhydrol. 2013.02.050.

SoilSurveyStaff (2014). Web soil survey, natural resources conservation service. USDA, .

Talling, P. J., \& Sowter, M. J. (1999). Drainage density on progressively tilted surfaces with different gradients, wheeler ridge, california. Earth Surface Processes and Landforms, 24, 809-824. doi:10.1002/(SICI) 1096-9837 (199908) 24:9<809: :AID-ESP13>3.0.CD;2-R.

Tarolli, P. (2014). High-resolution topography for understanding earth surface processes: opportunities and challenges. Geomorphology, 216, 295312. doi:10.1016/j.geomorph.2014.03.008. 
Tarolli, P., \& Dalla Fontana, G. (2009). Hillslope-to-valley transition morphology: New opportunities from high resolution DTMs. Geomorphology, 113, 47-56. doi:10.1016/j.geomorph.2009.02.006.

Thornthwaite, C. W. (1931). The climates of north america: according to a new classification. Geographical Review, 21, 633-655.

Tucker, G. E., \& Bras, R. L. (1998). Hillslope processes, drainage density, and landscape morphology. Water Resources Research, 36, 1953-1964.

Ulusay, R., \& Hudson, J. A. (2007). The complete ISRM suggested methods for rock characterization, testing and monitoring: 1974-2006. International Society for Rock Mechanics, Commission on Testing Methods. 
Table 1: Principal component loading matrix of the variables analyzed

\begin{tabular}{l|c|c|c|c|c|c|c}
\hline Parameters & PC1 & PC2 & PC3 & PC4 & PC5 & PC6 & PC7 \\
\hline$V_{\text {cov }}$ & 0.55 & -0.01 & 0.12 & -0.04 & -0.13 & 0.51 & -0.64 \\
$D_{d d}$ & -0.14 & -0.49 & 0.62 & -0.38 & -0.42 & -0.16 & -0.02 \\
Relief & 0.39 & -0.27 & 0.28 & 0.67 & 0.17 & -0.47 & -0.05 \\
UCS & 0.19 & -0.48 & -0.63 & 0.11 & -0.54 & 0.01 & 0.17 \\
AWC & 0.43 & 0.27 & -0.19 & -0.52 & -0.02 & -0.65 & -0.14 \\
THICK & 0.15 & 0.60 & 0.25 & 0.25 & -0.63 & 0.03 & 0.31 \\
MAP & 0.53 & -0.14 & 0.15 & -0.25 & 0.29 & 0.29 & 0.67 \\
\hline
\end{tabular}

third component indicates that variance in rock strength and drainage density are also inversely proportional. 


\begin{tabular}{|c|c|c|c|c|c|}
\hline Label & State & BasinName & NLCD & UnitAge & lithology \\
\hline 1 & California & Badlands I & 8 & Cenozoic & sedimentary \\
\hline 2 & California & Badlands II & 16 & Cenozoic & sedimentary \\
\hline 3 & California & Badlands III & 16 & Cenozoic & sedimentary \\
\hline 4 & California & Badlands IV & 16 & Cenozoic & sedimentary \\
\hline 5 & California & Badlands V & 16 & Cenozoic & sedimentary \\
\hline 6 & California & Badlands VI & 16 & Cenozoic & sedimentary \\
\hline 7 & California & Earthscope I & 7 & Mesozoic & plutonic rock \\
\hline 8 & California & Earthscope II & 7 & Mesozoic & plutonic rock \\
\hline 9 & California & Earthscope III & 7 & Mesozoic & plutonic rock \\
\hline 10 & California & Earthscope IV & 7 & Mesozoic & plutonic rock \\
\hline 11 & California & Earthscope V & 7 & Mesozoic & plutonic rock \\
\hline 12 & California & Earthscope VI & 7 & Mesozoic & plutonic rock \\
\hline 13 & California & Earthscope VII & 7 & Mesozoic & plutonic rock \\
\hline 14 & California & Earthscope VIII & 7 & Cenozoic & sedimentary \\
\hline 15 & California & Earthscope IX & 7 & Cenozoic & sedimentary \\
\hline 16 & California & Earthscope X & 7 & Cenozoic & unconsolidated \\
\hline 17 & California & Earthscope XI & 7 & Cenozoic & unconsolidated \\
\hline 18 & California & Earthscope XII & 7 & Cenozoic & sedimentary \\
\hline 19 & California & Earthscope XIII & 7 & Cenozoic & sedimentary \\
\hline 20 & California & Earthscope XIV & 7 & Cenozoic & sedimentary \\
\hline 21 & Idaho & Salmon Creek I & 8 & Mesozoic & plutonic rock \\
\hline 22 & Idaho & Salmon Creek II & 8 & Mesozoic & plutonic rock \\
\hline 23 & Idaho & Salmon Creek III & 8 & Mesozoic & plutonic rock \\
\hline 24 & Idaho & Salmon Creek IV & 8 & Mesozoic & plutonic rock \\
\hline 25 & Idaho & Salmon Creek V & 8 & Mesozoic & plutonic rock \\
\hline 26 & Idaho & Salmon Creek VI & 8 & Mesozoic & plutonic rock \\
\hline 27 & Idaho & Salmon Creek VII & 8 & Mesozoic & plutonic rock \\
\hline 28 & Idaho & Salmon Creek VIII & 8 & Mesozoic & plutonic rock \\
\hline 29 & Idaho & Salmon Creek IX & 8 & Mesozoic & plutonic rock \\
\hline 30 & Utah & Little Salt lake I & 1 & Cenozoic & volcanic rock \\
\hline 31 & Utah & Little Salt lake II & 1 & Cenozoic & volcanic rock \\
\hline 32 & Utah & Little Salt lake III & 1 & Cenozoic & volcanic rock \\
\hline 33 & Utah & Little Salt lake IV & 1 & Mesozoic & sedimentary \\
\hline 34 & Utah & Little Salt lake V & 8 & Mesozoic & sedimentary \\
\hline 35 & Utah & Little Salt lake VI & 8 & Mesozoic & sedimentary \\
\hline
\end{tabular}

Table 2: Land cover and lithology groups of study sites. The NLCD are the class value in national land cover database http://www.mrlc.gov/nlcd06_leg.php 
Table 2: Continued... Land cover and lithology groups of study sites. The NLCD are the class value in national land cover database http://www.mrlc.gov/nlcd06_leg.php

\begin{tabular}{|c|c|c|c|c|c|}
\hline Label & State & BasinName & NLCD & UnitAge & lithology \\
\hline 36 & Utah & Dairy Hill I & 8 & Cenozoic & sedimentary \\
\hline 37 & Utah & Dairy Hill II & 8 & Cenozoic & sedimentary \\
\hline 38 & Utah & Dairy Hill III & 8 & Cenozoic & sedimentary \\
\hline 39 & Utah & Dairy Hill IV & 8 & Cenozoic & sedimentary \\
\hline 40 & Utah & Dairy Hill V & 8 & Cenozoic & sedimentary \\
\hline 41 & North Carolina & Smoky Mnts I & 5 & Proterozoic & metamorphic rock \\
\hline 42 & North Carolina & Smoky Mnts II & 5 & Proterozoic & metamorphic rock \\
\hline 43 & North Carolina & Smoky Mnts III & 5 & Proterozoic & metamorphic rock \\
\hline 44 & North Carolina & Nantahala NF I & 5 & Proterozoic & metamorphic rock \\
\hline 45 & North Carolina & Nantahala NF II & 5 & Proterozoic & metamorphic rock \\
\hline 46 & North Carolina & $\begin{array}{l}\text { Nantahala } \mathrm{NF} \\
\text { III }\end{array}$ & 5 & Proterozoic & metamorphic rock \\
\hline 47 & North Carolina & $\begin{array}{l}\text { Nantahala NF } \\
\text { IV }\end{array}$ & 5 & Proterozoic & metamorphic rock \\
\hline 48 & North Carolina & Nantahala NF V & 5 & Proterozoic & metamorphic rock \\
\hline 49 & Alabama & Malone Creek & 1 & Mesozoic & unconsolidated \\
\hline 50 & Alabama & Malone Creek I & 5 & Mesozoic & unconsolidated \\
\hline 51 & Alabama & Malone Creek II & 5 & Mesozoic & unconsolidated \\
\hline 52 & Alabama & $\begin{array}{ll}\text { Malone } & \text { Creek } \\
\text { III } & \\
\end{array}$ & 5 & Mesozoic & unconsolidated \\
\hline 53 & Indiana & PPT1080 I & 5 & Paleozoic & sedimentary \\
\hline 54 & Indiana & PPT1080 II & 5 & Paleozoic & sedimentary \\
\hline 55 & Indiana & PPT1080 III & 5 & Paleozoic & sedimentary \\
\hline 56 & Pennsylvania & Shale Hills I & 15 & Paleozoic & sedimentary \\
\hline 57 & Pennsylvania & Shale Hills II & 5 & Paleozoic & sedimentary \\
\hline 58 & Pennsylvania & Shale Hills III & 5 & Paleozoic & sedimentary \\
\hline 59 & Indiana & PPT1100 I & 5 & Paleozoic & sedimentary \\
\hline 60 & Indiana & PPT1100 II & 5 & Paleozoic & sedimentary \\
\hline 61 & Indiana & PPT1100 III & 5 & Paleozoic & sedimentary \\
\hline 62 & Indiana & PPT1200 I & 5 & Paleozoic & sedimentary \\
\hline 63 & Indiana & PPT1200 II & 5 & Paleozoic & sedimentary \\
\hline 64 & Indiana & PPT1200 III & 5 & Paleozoic & sedimentary \\
\hline 65 & Washington & West Rainier I & 8 & Cenozoic & sedimentary \\
\hline 66 & Washington & West Rainier II & 8 & Cenozoic & sedimentary \\
\hline 67 & Washington & West Rainier III & 1 & Cenozoic & sedimentary \\
\hline 68 & Washington & West Rainier IV & 8 & Cenozoic & sedimentary \\
\hline 69 & Washington & West Rainier V & 1 & Cenozoic & sedimentary \\
\hline 70 & Washington & West Rainier VI & 8 & Cenozoic & sedimentary \\
\hline
\end{tabular}


Table 2: Continued... Land cover and lithology groups of study sites. The NLCD are the class value in national land cover database http://www.mrlc.gov/nlcd06_leg.php

\begin{tabular}{|c|c|c|c|c|c|}
\hline Label & State & BasinName & NLCD & UnitAge & lithology \\
\hline 71 & Washington & West Rainier VII & 8 & Cenozoic & sedimentary \\
\hline 72 & Washington & West Rainier VIII & 1 & Cenozoic & sedimentary \\
\hline 73 & Oregon & Basaltic basin part1 - I & 8 & Cenozoic & volcanic rock \\
\hline 74 & Oregon & Basaltic basin part1 - II & 8 & Cenozoic & volcanic rock \\
\hline 75 & Oregon & Basaltic basin part1 - I & 1 & Cenozoic & volcanic rock \\
\hline 76 & Oregon & Basaltic basin part1 - I & 8 & Cenozoic & volcanic rock \\
\hline 77 & Oregon & Basaltic basin part2 -I & 1 & Cenozoic & volcanic rock \\
\hline 78 & Arizona & Finley and Adams Canyon I & 1 & Mesozoic & volcanic rock \\
\hline 79 & Arizona & Finley and Adams Canyon II & 1 & Mesozoic & volcanic rock \\
\hline 80 & Arizona & Sycamore canyon I & 1 & Mesozoic & plutonic rock \\
\hline 81 & Arizona & Sycamore canyon II & 1 & Mesozoic & plutonic rock \\
\hline 82 & Colorado & Delonde gulch & 1 & Proterozoic & plutonic rock \\
\hline 83 & Colorado & Hicks gulch & 1 & Proterozoic & metamorphic rock \\
\hline 84 & New Mexico & Paso del Norte Basin & 1 & Cenozoic & volcanic rock \\
\hline 85 & New Mexico & Paso del Norte Basin I & 1 & Cenozoic & volcanic rock \\
\hline 86 & New Mexico & Paso del Norte Basin II & 1 & Cenozoic & volcanic rock \\
\hline 87 & Utah & Maple hollow & 8 & Paleozoic & sedimentary \\
\hline 88 & Utah & Mercer hollow & 10 & Cenozoic & volcanic rock \\
\hline 89 & Oregon & Basaltic basin part3 -I & 8 & Cenozoic & volcanic rock \\
\hline 90 & Oregon & Basaltic basin part3 -II & 8 & Cenozoic & volcanic rock \\
\hline 91 & Oregon & Basaltic basin part3 -III & 8 & Cenozoic & volcanic rock \\
\hline 92 & Oregon & Basaltic basin part4 -I & 6 & Cenozoic & volcanic rock \\
\hline 93 & Oregon & Basaltic basin part4 -II & 6 & Cenozoic & volcanic rock \\
\hline 94 & Oregon & Basaltic basin part4 -III & 1 & Cenozoic & volcanic rock \\
\hline 95 & Oregon & Basaltic basin part4 -IV & 1 & Cenozoic & volcanic rock \\
\hline 96 & Virginia & Piedmont I & 5 & Paleozoic & metamorphic rock \\
\hline 97 & Virginia & Piedmont II & 5 & Paleozoic & metamorphic rock \\
\hline 98 & Virginia & Piedmont III & 5 & Paleozoic & metamorphic rock \\
\hline 99 & California & NAPA I & 10 & Cenozoic & sedimentary \\
\hline 100 & California & NAPA II & 10 & Cenozoic & sedimentary \\
\hline 101 & New Mexico & Crater basin I & 1 & Cenozoic & volcanic rock \\
\hline
\end{tabular}


Table 3: Climate and soil parameters of the study sites

\begin{tabular}{|c|c|c|c|c|c|c|c|c|c|c|}
\hline Label & $M A P[\mathrm{~mm} / \mathrm{yr}]$ & $D_{d d}[-]$ & $D_{g}\left[\mathrm{~m} / \mathrm{km}^{2}\right]$ & AWC [-] & Clay $[\%]$ & KFFACT & PERM [in/hr] & THICK [in] & $P F D$ & RUNOFF \\
\hline 1 & 76 & 0.076 & 22499.56 & 0.04 & 9.7 & 0.15 & 4.79 & 1447.8 & 11.2522 & 16.5862 \\
\hline 2 & 76 & 0.114 & 30191.40 & 0.04 & 9.7 & 0.15 & 4.79 & 1447.8 & 11.684 & 17.018 \\
\hline 3 & 76 & 0.099 & 23127.10 & 0.04 & 9.7 & 0.15 & 4.79 & 1447.8 & 11.2522 & 16.5862 \\
\hline 4 & 79 & 0.090 & 23665.75 & 0.04 & 9.7 & 0.15 & 4.79 & 1447.8 & 11.2522 & 16.5862 \\
\hline 5 & 81 & 0.109 & 26640.15 & 0.04 & 9.7 & 0.15 & 4.79 & 1447.8 & 11.4808 & 16.8148 \\
\hline 6 & 82 & 0.092 & 25034.27 & 0.04 & 9.7 & 0.15 & 4.79 & 1447.8 & 11.684 & 17.018 \\
\hline 7 & 172 & 0.061 & 9878.87 & 0.05 & 12.9 & 0.14 & 2.61 & 1013.46 & 11.4808 & 72.1868 \\
\hline 8 & 177 & 0.075 & 13549.02 & 0.05 & 12.9 & 0.14 & 2.61 & 1013.46 & 11.5951 & 72.3011 \\
\hline 9 & 172 & 0.046 & 9415.57 & 0.05 & 12.9 & 0.14 & 2.61 & 1013.46 & 11.4808 & 72.1868 \\
\hline 10 & 172 & 0.063 & 11994.57 & 0.05 & 12.9 & 0.14 & 2.61 & 1013.46 & 11.4808 & 72.1868 \\
\hline 11 & 165 & 0.086 & 8247.02 & 0.05 & 12.9 & 0.14 & 2.61 & 1013.46 & 11.4046 & 72.1106 \\
\hline 12 & 172 & 0.078 & 13703.45 & 0.05 & 12.9 & 0.14 & 2.61 & 1013.46 & 11.4808 & 72.1868 \\
\hline 13 & 167 & 0.064 & 8893.14 & 0.05 & 12.9 & 0.14 & 2.61 & 1013.46 & 11.3792 & 72.0852 \\
\hline 14 & 148 & 0.096 & 16887.39 & 0.05 & 12.9 & 0.14 & 2.61 & 1013.46 & 11.0998 & 71.8058 \\
\hline 15 & 148 & 0.102 & 13621.39 & 0.05 & 12.9 & 0.14 & 2.61 & 1013.46 & 11.0998 & 71.8058 \\
\hline 16 & 143 & 0.080 & 14425.30 & 0.05 & 12.9 & 0.14 & 2.61 & 1013.46 & 11.0998 & 71.8058 \\
\hline 17 & 140 & 0.098 & 9680.33 & 0.05 & 12.9 & 0.14 & 2.61 & 1013.46 & 10.9982 & 71.7042 \\
\hline 18 & 161 & 0.090 & 12681.01 & 0.05 & 12.9 & 0.14 & 2.61 & 1013.46 & 11.2776 & 71.9836 \\
\hline 19 & 162 & 0.101 & 12304.50 & 0.05 & 12.9 & 0.14 & 2.61 & 1013.46 & 11.303 & 72.009 \\
\hline 20 & 161 & 0.079 & 10526.60 & 0.05 & 12.9 & 0.14 & 2.61 & 1013.46 & 11.3284 & 72.0344 \\
\hline 21 & 646 & 0.058 & 5536.12 & 0.07 & 6 & 0.21 & 11.43 & 1549.4 & NA & NA \\
\hline 22 & 646 & 0.070 & 8845.24 & 0.07 & 6 & 0.21 & 11.43 & 1549.4 & NA & NA \\
\hline 23 & 646 & 0.079 & 14793.17 & 0.07 & 6 & 0.21 & 11.43 & 1549.4 & $\mathrm{NA}$ & NA \\
\hline 24 & 641 & 0.037 & 8035.19 & 0.07 & 6 & 0.21 & 11.43 & 1549.4 & NA & NA \\
\hline 25 & 646 & 0.077 & 13310.10 & 0.07 & 6 & 0.21 & 11.43 & 1549.4 & $\mathrm{NA}$ & NA \\
\hline 26 & 646 & 0.089 & 14522.58 & 0.07 & 6 & 0.21 & 11.43 & 1549.4 & NA & NA \\
\hline 27 & 645 & 0.069 & 11079.47 & 0.07 & 6 & 0.21 & 11.43 & 1549.4 & NA & NA \\
\hline 28 & 644 & 0.056 & 8412.51 & 0.07 & 6 & 0.21 & 11.43 & 1549.4 & NA & NA \\
\hline 29 & 641 & 0.031 & 6066.53 & 0.07 & 6 & 0.21 & 11.43 & 1549.4 & NA & NA \\
\hline 30 & 500 & 0.109 & 21997.50 & 0.15 & 35 & 0.29 & 0.47 & 1564.64 & 25.7556 & 140.8176 \\
\hline 31 & 562 & 0.080 & 11420.70 & 0.15 & 35 & 0.29 & 0.47 & 1564.64 & 27.432 & 142.494 \\
\hline 32 & 526 & 0.076 & 11114.08 & 0.15 & 35 & 0.29 & 0.47 & 1564.64 & 26.7208 & 141.7828 \\
\hline 33 & 440 & 0.121 & 16493.17 & 0.15 & 35 & 0.29 & 0.47 & 1564.64 & 24.6888 & 139.7508 \\
\hline 34 & 490 & 0.104 & 17552.64 & 0.15 & 35 & 0.29 & 0.47 & 1564.64 & 26.0096 & 141.0716 \\
\hline 35 & 490 & 0.127 & 17467.16 & 0.15 & 35 & 0.29 & 0.47 & 1564.64 & 26.0096 & 141.0716 \\
\hline 36 & 323 & 0.079 & 12733.62 & 0.09 & 26.6 & 0.21 & 1.19 & 960.12 & 20.193 & 116.967 \\
\hline 37 & 322 & 0.108 & 21278.70 & 0.09 & 26.6 & 0.21 & 1.19 & 960.12 & 20.2946 & 117.0686 \\
\hline 38 & 324 & 0.070 & 9233.93 & 0.09 & 26.6 & 0.21 & 1.19 & 960.12 & 20.2692 & 117.0432 \\
\hline 39 & 321 & 0.101 & 12783.20 & 0.09 & 26.6 & 0.21 & 1.19 & 960.12 & 20.2438 & 117.0178 \\
\hline 40 & 320 & 0.089 & 14159.42 & 0.09 & 26.6 & 0.21 & 1.19 & 960.12 & 20.0914 & 116.8654 \\
\hline
\end{tabular}


Table 3: Continued... Climate and soil parameters of the study sites

\begin{tabular}{|c|c|c|c|c|c|c|c|c|c|c|}
\hline Label & $M A P[\mathrm{~mm} / \mathrm{yr}]$ & $D_{d d}[-]$ & $D_{g}\left[\mathrm{~m} / \mathrm{km}^{2}\right]$ & AWC [-] & Clay [\%] & KFFACT & PERM [in/hr] & THICK [in] & $P F D$ & RUNOFF \\
\hline 41 & 1626 & 0.032 & 5276.38 & 0.12 & 10.9 & 0.23 & 3.81 & 1374.14 & 51.8922 & 82.1182 \\
\hline 42 & 1626 & 0.061 & 9837.93 & 0.12 & 10.9 & 0.23 & 3.81 & 1374.14 & 52.324 & 82.55 \\
\hline 43 & 1626 & 0.088 & 14611.60 & 0.1 & 14.5 & 0.21 & 2.97 & 1559.56 & 51.9176 & 103.4796 \\
\hline 44 & 1972.5 & 0.071 & 14932.64 & 0.13 & 17.1 & 0.23 & 2.72 & 1493.52 & 51.1302 & 109.0422 \\
\hline 45 & 2009 & 0.068 & 9841.97 & 0.13 & 17.1 & 0.23 & 2.72 & 1493.52 & 51.7398 & 109.6518 \\
\hline 46 & 2009 & 0.071 & 16431.73 & 0.13 & 17.1 & 0.23 & 2.72 & 1493.52 & 51.7398 & 109.6518 \\
\hline 47 & 2006 & 0.072 & 15392.58 & 0.13 & 17.1 & 0.23 & 2.72 & 1493.52 & 51.7398 & 109.6518 \\
\hline 48 & 2006 & 0.065 & 13243.95 & 0.13 & 17.1 & 0.23 & 2.72 & 1493.52 & 51.6636 & 109.5756 \\
\hline 49 & 1388 & 0.032 & 10422.86 & 0.15 & 28.3 & 0.29 & 2.32 & 1874.52 & 53.2892 & 121.3612 \\
\hline 50 & 1389 & 0.066 & 18630.62 & 0.15 & 28.3 & 0.29 & 2.32 & 1874.52 & 53.3146 & 121.3866 \\
\hline 51 & 1388 & 0.021 & 6406.63 & 0.15 & 28.3 & 0.29 & 2.32 & 1874.52 & 53.2892 & 121.3612 \\
\hline 52 & 1388 & 0.036 & 14463.07 & 0.15 & 28.3 & 0.29 & 2.32 & 1874.52 & 53.2892 & 121.3612 \\
\hline 53 & 1097 & 0.066 & 18690.25 & 0.16 & 26 & 0.28 & 1.43 & 1696.72 & 45.9994 & 136.6774 \\
\hline 54 & 1097 & 0.056 & 15006.12 & 0.16 & 26 & 0.28 & 1.43 & 1696.72 & 46.0248 & 136.7028 \\
\hline 55 & 1096 & 0.069 & 17986.80 & 0.16 & 26 & 0.28 & 1.43 & 1696.72 & 45.9994 & 136.6774 \\
\hline 56 & 1016 & 0.042 & 10774.77 & 0.11 & 34.5 & 0.26 & 1.93 & 1036.32 & 38.1 & 116.078 \\
\hline 57 & 1013 & 0.064 & 18734.61 & 0.11 & 34.5 & 0.26 & 1.93 & 1036.32 & 38.0746 & 116.0526 \\
\hline 58 & 1013 & 0.054 & 16537.59 & 0.11 & 34.5 & 0.26 & 1.93 & 1036.32 & 38.1 & 116.078 \\
\hline 59 & 1180 & 0.050 & 10827.02 & 0.11 & 22.2 & 0.3 & 2.31 & 1089.66 & 45.4152 & 113.7412 \\
\hline 60 & 1179 & 0.057 & 11329.32 & 0.11 & 22.2 & 0.3 & 2.31 & 1089.66 & 45.4406 & 113.7666 \\
\hline 61 & 1179 & 0.070 & 12072.16 & 0.11 & 22.2 & 0.3 & 2.31 & 1089.66 & 45.4152 & 113.7412 \\
\hline 62 & 1241 & 0.081 & 8042.08 & 0.14 & 24.1 & 0.35 & 1.37 & 1318.26 & 44.5516 & 136.7536 \\
\hline 63 & 1241 & 0.071 & 9142.05 & 0.14 & 24.1 & 0.35 & 1.37 & 1318.26 & 44.5008 & 136.7028 \\
\hline 64 & 1241 & 0.068 & 6312.46 & 0.14 & 24.1 & 0.35 & 1.37 & 1318.26 & 44.5008 & 136.7028 \\
\hline 65 & 1999 & 0.076 & 13249.97 & 0.08 & 4 & 0.21 & 7.69 & 1470.66 & NA & NA \\
\hline 66 & 1963 & 0.058 & 11363.06 & 0.08 & 4 & 0.21 & 7.69 & 1470.66 & NA & NA \\
\hline 67 & 2070 & 0.069 & 18222.80 & 0.08 & 4 & 0.21 & 7.69 & 1470.66 & NA & NA \\
\hline 68 & 2070 & 0.106 & 22259.90 & 0.08 & 4 & 0.21 & 7.69 & 1470.66 & NA & NA \\
\hline 69 & 2102 & 0.085 & 24886.42 & 0.08 & 4 & 0.21 & 7.69 & 1470.66 & NA & NA \\
\hline 70 & 2102 & 0.095 & 22191.87 & 0.08 & 4 & 0.21 & 7.69 & 1470.66 & $\mathrm{NA}$ & NA \\
\hline 71 & 2107 & 0.039 & 10886.40 & 0.08 & 4 & 0.21 & 7.69 & 1470.66 & $\mathrm{NA}$ & NA \\
\hline 72 & 1977 & 0.077 & 13945.35 & 0.08 & 4 & 0.21 & 7.69 & 1470.66 & NA & NA \\
\hline 73 & 461 & 0.068 & 24353.11 & 0.14 & 32.8 & 0.3 & 0.85 & 1181.1 & NA & NA \\
\hline 74 & 454 & 0.049 & 15520.24 & 0.14 & 32.8 & 0.3 & 0.85 & 1181.1 & $\mathrm{NA}$ & NA \\
\hline 75 & 535 & 0.049 & 13019.88 & 0.14 & 32.8 & 0.3 & 0.85 & 1181.1 & NA & NA \\
\hline 76 & 418.5 & 0.061 & 9868.93 & 0.14 & 32.8 & 0.3 & 0.85 & 1181.1 & NA & NA \\
\hline 77 & 835 & 0.066 & 20216.19 & 0.14 & 19.9 & 0.35 & 1.53 & 1216.66 & NA & NA \\
\hline 78 & 539 & 0.079 & 10892.80 & 0.07 & 18.9 & 0 & 0.54 & 744.22 & 44.704 & 157.988 \\
\hline 79 & 539 & 0.074 & 9234.06 & 0.07 & 18.9 & 0 & 0.54 & 744.22 & 44.831 & 158.115 \\
\hline 80 & 549 & 0.068 & 7912.13 & 0.07 & 18.9 & 0 & 0.54 & 744.22 & 45.31995 & 158.60395 \\
\hline
\end{tabular}


Table 3: Continued... Climate and soil parameters of the study sites

\begin{tabular}{l|c|c|c|c|c|c|c|c|c|c}
\hline Label & $M A P[\mathrm{~mm} / \mathrm{yr}]$ & $D_{d d}[-]$ & $D_{g}\left[\mathrm{~m} / \mathrm{km}^{2}\right]$ & AWC $[-]$ & Clay $[\%]$ & KFFACT & PERM $[\mathrm{in} / \mathrm{hr}]$ & THICK $[\mathrm{in}]$ & $P F D$ & RUNOFF \\
\hline 81 & 549 & 0.084 & 9726.11 & 0.07 & 18.9 & 0 & 0.54 & 744.22 & 45.3898 & 158.6738 \\
\hline 82 & 604 & 0.049 & 20064.61 & 0.06 & 19.5 & 0.3 & 2.95 & 1363.98 & 22.1488 & 74.2188 \\
\hline 83 & 727 & 0.054 & 13950.63 & 0.06 & 10.6 & 0.18 & 5.16 & 1478.28 & 22.225 & 18.161 \\
\hline 84 & 668 & 0.058 & 9189.83 & 0.07 & 14.3 & 0 & 5.46 & 1450.34 & 31.4833 & 19.7993 \\
\hline 85 & 668 & 0.057 & 8059.04 & 0.07 & 14.3 & 0 & 5.46 & 1450.34 & 31.5468 & 19.8628 \\
\hline 86 & 668 & 0.045 & 8518.98 & 0.07 & 14.3 & 0 & 5.46 & 1450.34 & 31.5468 & 19.8628 \\
\hline 87 & 583 & 0.067 & 10382.60 & 0.08 & 24.9 & 0.26 & 2.29 & 1584.96 & 18.415 & 87.249 \\
\hline 88 & 590 & 0.057 & 9673.37 & 0.08 & 24.9 & 0.26 & 2.29 & 1584.96 & 18.4912 & 87.3252 \\
\hline 89 & 3611 & 0.055 & 14622.03 & 0.17 & 20 & 0.28 & 1.2 & 1168.4 & NA & NA \\
\hline 90 & 3620 & 0.067 & 11955.13 & 0.17 & 20 & 0.28 & 1.2 & 1168.4 & NA & NA \\
\hline 91 & 3741 & 0.086 & 15502.97 & 0.17 & 20 & 0.28 & 1.2 & 1168.4 & NA & NA \\
\hline 92 & 2729 & 0.065 & 15859.17 & 0.19 & 19.4 & 0.25 & 1.4 & 1226.82 & NA & NA \\
\hline 93 & 2729 & 0.077 & 19419.05 & 0.19 & 19.4 & 0.25 & 1.4 & 1226.82 & NA & NA \\
\hline 94 & 2739.5 & 0.053 & 13751.85 & 0.19 & 19.4 & 0.25 & 1.4 & 1226.82 & NA & NA \\
\hline 95 & 2729 & 0.093 & 18525.39 & 0.19 & 19.4 & 0.25 & 1.4 & 1226.82 & NA & NA \\
\hline 96 & 1056 & 0.052 & 12683.56 & 0.12 & 28.1 & 0.26 & 2.38 & 1747.52 & 46.482 & 113.03 \\
\hline 97 & 1056 & 0.051 & 9400.29 & 0.12 & 28.1 & 0.26 & 2.38 & 1747.52 & 46.482 & 113.03 \\
\hline 98 & 1055 & 0.065 & 18829.53 & 0.12 & 28.1 & 0.26 & 2.38 & 1747.52 & 46.5328 & 113.0808 \\
\hline 99 & 673 & 0.048 & 8278.27 & 0.15 & 37.2 & 0.35 & 0.31 & 1272.54 & 17.7546 & 136.8806 \\
\hline 100 & 673 & 0.065 & 11617.63 & 0.15 & 37.2 & 0.35 & 0.31 & 1272.54 & 17.8562 & 136.9822 \\
\hline 101 & 712 & 0.064 & 11602.59 & 0.07 & 14.3 & 0 & 5.46 & 1450.34 & 33.0708 & 21.3868 \\
\hline
\end{tabular}

